Portland State University

PDXScholar

$1-1-2011$

\title{
Toward a Taxonomy of Diversity at Work: Developing and Validating the Workplace Diversity Inventory
}

Aisha Smith Taylor

Portland State University

Follow this and additional works at: https://pdxscholar.library.pdx.edu/open_access_etds

Let us know how access to this document benefits you.

\section{Recommended Citation}

Taylor, Aisha Smith, "Toward a Taxonomy of Diversity at Work: Developing and Validating the Workplace Diversity Inventory" (2011). Dissertations and Theses. Paper 158.

https://doi.org/10.15760/etd.158

This Thesis is brought to you for free and open access. It has been accepted for inclusion in Dissertations and Theses by an authorized administrator of PDXScholar. Please contact us if we can make this document more accessible: pdxscholar@pdx.edu. 
Toward a Taxonomy of Diversity at Work:

Developing and Validating the Workplace Diversity Inventory

by

Aisha Smith Taylor

A thesis submitted in partial fulfillment of the requirements for the degree of

\author{
Master of Science \\ in \\ Psychology
}

Thesis Committee:

Keith James, Chair

Todd Bodner

Liu-Qin Yang

Portland State University

(C)2011 
Taxonomy of Workplace Diversity i

\begin{abstract}
The purpose of this research was to develop a taxonomy of workplace diversity and examine its implications for understanding and predicting diversity at work. A 7dimension taxonomy was originally developed by reviewing contemporary literature on diversity in the workplace. The taxonomy is grounded in Social Identity Theory. Preliminary research found that each of the seven dimensions of the taxonomy were present in 78 critical incidents describing work-relevant diversity dynamics. The current study reports the development and administration of an instrument, the Workplace Diversity Inventory (WDI), which was used to empirically examine the 7-factor model of the taxonomy in over 20 different industries. Exploratory factor analysis using data from 209 respondents supported a six-dimension taxonomy, with one factor from the proposed taxonomy (Leadership) collapsed into two of the included WDI dimensions (Diversity Climate and Organizational Justice). Subsequent confirmatory factor analysis indicated an adequate to good fit for the six-factor model, with the WDI reduced from 47 to 24 items. Results and implications for theory and practice are discussed.
\end{abstract}


Table of Contents

Abstract

List of Tables

iii

List of Figures

iv

Introduction

Defining Workplace Diversity

1

Social Identity and Self-Categorization Theories

5

Taxonomy of Workplace Diversity

7

Summary of Diversity Measurement Literature

Convergent and Discriminant Validity Measures

Workplace Diversity Taxonomy Construct Model

Preliminary Research on Workplace Diversity

Method

Item Development

Participants

Measures

Data Analyses

Results

Testing and reducing the WDI

Testing the validity of the WDI-24

Exploratory Analyses

Discussion

Summary of Findings

Limitations

60

Future Research

Implications

66

Conclusion

Figures \& Tables

References

Appendices

A. Workplace Diversity Inventory-24 105

B. Workplace Prejudice/Discrimination Inventory 107

C. Colquitt Organizational Justice 108

D. Negative Affect

110

E. Safety Climate 
List of Tables

Table 1. Taxonomy of Workplace Diversity 74

Table 2 Industries Represented in Sample $\quad 75$

Table 3a-g. $\quad$ Item Analyses of the WDI Dimensions 76-80

Table $4 \quad$ Cronbach's Alpha and Fit Statistics for Validity Measures $\quad 81$

Table $5 \quad$ Initial Results of Confirmatory Factor Analyses on each 81 Dimension (6-7 items)

Table 6 Results of Confirmatory Factor Analyses on each Dimension $\quad 82$ with Items Deleted

Table $7 \quad$ Descriptive Statistics and Reliability Coefficients of Workplace 83 Diversity Dimensions

Table 8 Item Loadings with Six Significant Workplace Diversity Factors, 84 from the Principle Components Analysis

Table 9 WDI-24 Items and Standardized Regression Weights from $\quad 85$ Confirmatory Factor Analysis

Table $10 \quad$ Correlations between the WDI-24 Dimensions 86

Table $11 \quad$ Fit Statistics for Alternative Models 86

Table 12 Correlations of WDI-24 Dimensions and Validity Scales 87

Table $13 \quad$ Correlations of Overall WDI-24 and Validity Scales 87

Table 14 Descriptive Statistics by Demographic Category 87 
Taxonomy of Workplace Diversity iv

\section{List of Figures}

Figure $1 \quad$ Average Values of Workplace Diversity Dimensions in

Preliminary Research

Figure 2 Workplace Diversity Taxonomy Construct Model 
Taxonomy of Workplace Diversity 1

\section{Introduction}

Workplace diversity is increasing, in the U.S. and internationally, and is increasingly important to organizational success (Cox, 2001; Mor Barak, 2005; Triandis, 2003). In contrast with that of previous generations, today's workforce is more heterogeneous in terms of many social categories (e.g., age, gender, ethnicity, national origin) and research suggests that this trend will continue into the future (Judy \& D’Amico, 1997). U.S. Census projections for the year 2050 are that ethnic minorities will account for at least $47 \%$ of the U.S. population (Thomas, 2005). Due to globalization, international workforces are much more common and workplaces have become more diverse than ever before (Haq, 2004). The reality of today's increasingly diverse workforce creates a vital need to appreciate and value differences in order to work more effectively with people from diverse groups and varied backgrounds.

The urgency of addressing workplace diversity is evidenced by the fact that explicit, as well as covert, forms of racial prejudice have been shown to influence hiring decisions (Dovidio \& Gaertner, 2000), and workplace discrimination has continued to increase (U.S. Equal Employment Opportunity Commission [EEOC], 2010), in spite of greater awareness, increased training, and more social condemnation of the issue. There is a social and moral imperative to build diverse and inclusive working environments.

While workplace diversity has been shown to have both positive and negative effects (e.g., Guzzo \& Dickson, 1996; Milliken \& Martins, 1996), scholars agree that effective leadership and management are vital to leveraging the benefits of workplace diversity (Cox, 1991; Stockdale and Cao, 2004; Dahm, Willems, Ivancevich and Graves, 2009). Effectively managing diversity leads to a number of organizational advantages, 
Taxonomy of Workplace Diversity 2

including greater inclusiveness, increased creativity and innovation, better decisionmaking capabilities, ultimately, performance gains (van Knippenberg \& Schippers, 2007). Organizations that focus on harnessing and nurturing diversity and inclusion will benefit by creating numerous opportunities for learning and growth

In a global economy, many jobs require individuals to learn to operate effectively in a variety of different countries and with individuals who possess different values and orientations than themselves (Black, 1990; Noe \& Ford, 1992). The need for managers and employees to operate effectively in diverse workforces has become increasingly vital due to the rapidly changing nature of today's work environments. However, scholars have not yet come to consensus on one consistent, operational definition of workplace diversity. In the past 20 years, scholars have developed at least thirty definitions of workplace diversity (Mor Barak, 2011). However, none of them provide a clear way to assess the psychological constructs present in diverse organizations. As a complex and elusive concept, diversity needs to be defined in terms that make it possible for organizations to measure, predict, and manage it effectively. It is not possible to either accurately research organizational diversity processes and outcomes or to specify the attributes of successful management of workplace diversity unless we have strong conceptual and measurement tools with which to work. To date, no published research has systematically defined the entire domain of workplace diversity, nor has any comprehensive measure of all major dimensions of workplace diversity been developed. Therefore, there is a need to develop a detailed operational definition of diversity in the workplace, and a measure that examines all of its components. Defining diversity is important in order to make subsequent advances in implementing organizational diversity 
Taxonomy of Workplace Diversity 3

initiatives, in training that provides the skills necessary to navigate and manage increasingly diverse workforces, and in selecting workers that will contribute to bringing about the positive outcomes of diversity. To do so, it is essential to have a solid understanding of the underlying dynamics in diverse organizations. Accordingly, the purpose of the present research is to describe the development of a cutting edge definition of workplace diversity and an instrument based on that definition, which enables precise measurement of the patterns and experiences of employees in diverse U.S.-based and international work settings.

In the present study, a taxonomy of workplace diversity and an instrument to empirically measure it, the Workplace Diversity Inventory (WDI), is developed and administered. Specifically, I empirically examine the factor structure of the WDI and attempt to establish convergent and discriminant validity by correlating its scores with those from other inventories measuring relevant constructs. This will enable me to establish evidence that the WDI is part of the nomological network of other theoretically related constructs (Cronbach \& Meehl, 1955).

Two constructs that are commonly used to describe and measure diversity at work is diversity climate and inclusion. Research has demonstrated that a positive diversity climate is vital to the success of diversity initiatives (Rynes \& Rosen, 1995; Kossek \& Zonia, 1993). Scholars agree that a major problem in today's diverse workforce is that many employees perceive that they are not fully included - that they are not valued as an integral part of their organizations (Mor Barak, 2011). The proposed taxonomy includes but also goes beyond diversity climate and the concept of inclusion-exclusion to incorporate all relevant factors that contribute to employees' perception of workplace 
Taxonomy of Workplace Diversity 4

diversity. The taxonomy encompasses the entire domain of interactions, values, attitudes (such as prejudice and openness), behaviors (such as discrimination and support), and organizational variables (such as supportive diversity policies and top management support) relevant to diversity that manifest at five system levels of an organization: individual, workgroup, supervisor, higher management, and organization.

Tomaskovic-Devey et al. (2006) reported that Black-White segregation in America's workplaces has remained essentially the same since the 1980s, thereby emphasizing the need for organizations to find ways to create truly diverse and inclusive work settings. There are also economic and legal forces that make it imperative for most organizations to at least attempt to effectively manage diversity. Economic forces, such as the tremendous growth in multinational strategic alliances and growth in the service sector, are changing the very nature of the workplace and work itself (Hays-Thomas, 2004). The changing legal climate is also a factor. In the United States, the Civil Rights Act of 1964, combined with Executive Order 11246, which promulgated affirmative action, were arguably the most important influences in spurring diversity-related outcomes and practices in U.S. organizations. Subsequent legal interpretations and updates to the Civil Rights Act, as well as new laws, have created a sophisticated legal structure that undergirds U.S. diversity practices (Stockdale \& Cao, 2004). Internationally, legal structures shape diversity practices in nations around the world (Haq, 2004). Therefore, organizations must strive to manage diversity well in order to avoid litigation.

Although diversity is not a new concept, researchers and practitioners are increasingly interested in understanding and managing workplace diversity in light of 
Taxonomy of Workplace Diversity 5

globalization. In addition to being a sub-discipline of Industrial/Organizational Psychology, diversity management is studied in many disciplines, such as Organizational Behavior, Human Resource Management, Organizational Sociology, and Political Science (Stockdale and Cao, 2004).

\section{Definitions of Workplace Diversity}

The term diversity is used often and in many different ways (Dass \& Parker, 1999). Mor Barak (2011) provides a typology that includes thirty definitions of diversity developed by scholars from 1991 to 2010 . Numerous authors have discussed diversity in relation to phenomena at the individual, team, and organizational levels, often using many different names and definitions for this concept (Stockdale and Cao, 2004; HaysThomas 2004). Thomas (2005) asserts that diversity refers to "those individual differences that are socially and historically significant and which have resulted in differences in power and privilege inside as well as outside of organizations (p. 9)." Crosby and Stockdale describe diverse work organizations as, "those in which the people who work together differ along the dimensions that society has deemed important" (2004, p. xiii). Cox (1994, p. 6) has written, "Cultural diversity means the representation, in one social system, of people with distinctly different group affiliations of cultural significance." He focuses on race, ethnicity, gender, and nationality because he believes these dimensions to be particularly important in social interaction. To support this claim, he states that these bases of identity, unlike religion or age, do not change and that there is substantial social research on these dimensions. Differences based on these social categories have been sensitive to discuss and extremely difficult to alter (Hays-Thomas, 
Taxonomy of Workplace Diversity 6

2004). In contrast to the above definitions, a broader approach was developed and promulgated by Roosevelt Thomas (1996), which downplays power differentials and treats all bases of difference, such as personality and professional background, as more or less equivalent in terms of systematic analyses (Hays-Thomas, 2004). Linnehan and Konrad (1999) argue against this approach, stating that it is vital to focus on the ways in which privilege, power, and inequality affect intergroup relations. While R. Thomas' approach has an important place in the research literature, it is of secondary interest in the present study. I focus on diversity among consequential social categories, not only within the U.S., but in the global workforce. In an attempt to address the limitations of both approaches, Mor Barak (2011) developed the following definition of global workforce diversity: "Workforce diversity refers to the division of the workforce into distinction categories that (a) have a perceived commonality within a given cultural or national context and that (b) impact potentially harmful or beneficial employment outcomes such as job opportunities, treatment in the workplace, and promotion prospects-irrespective of job-related skills and qualifications (p.148)." This definition provides a broad umbrella that includes any categories that may be relevant to specific cultural or national environments, thus allowing the inclusion of categories that may be relevant in some cultural contexts and not in others (e.g., regional differences, HIV status). However, it also emphasizes the importance of the consequences of social categorization in terms of its potential to affect important workplace outcomes, which address the limitation of broad definitions of diversity that include inconsequential characteristics. In order to identify what is important and to enable researchers to clearly define variables, there should be shared understanding and agreement regarding the 
Taxonomy of Workplace Diversity 7

definition of diversity across organizational variables. The social categories that were included in the current study include ethnicity, race, national origin, culture, gender, gender identity, sexual orientation, religion/faith, socioeconomic status, disability and age. However, instead of providing a working definition for the present study, the proposed taxonomy is provided as an alternative to other definitions, and thus, is in itself a definition of workplace diversity. The WDI based on the taxonomy is offered in an attempt to provide an operational definition of diversity that enables scholars and practitioners to measure the entire construct in a consistent manner.

\section{Social Identity and Self-Categorization Theories}

Social identity (Tajfel \& Turner, 1986) and self-categorization (Turner, 1987) theories posit that individuals classify themselves and others into personally meaningful groups. These groups may include demographic categories, such as those mentioned above. These classifications are important because individuals use them to draw distinctions between in-group and out-group members (Avery, McKay \& Wilson, 2007). Because individuals have a strong desire to maintain and enhance their own self esteem, they tend to "(a) respond unfavorably to social identity threats, such as discrimination, (b) exhibit bias in favor of in-group members; and (c) seek information affirming identification with in-group membership" (Avery, McKay \& Wilson, 2007, p. 1543). The motivation to preserve a positive identity drives individuals' cognitions, emotions and behaviors (James, Lovato, \& Cropanzano, 1994).

Maintaining positive in-group characteristics are important for an individual to maintain a positive sense of self-worth; however, these theories predict that evaluations 
Taxonomy of Workplace Diversity 8

of in-group characteristics are made possible through comparisons of the in-group and out-group. The distinctions made between in-group and out-group membership has the potential to bring about negative consequences at work, especially for those who are perceived to be in the minority of the relevant social category (James et al., 1994). This often happens "when the characteristic(s) on which that grouping is based are normatively associated with low status and negative stereotypes" (James et al., 1994, p. 1575).

Social identity-based diversity dynamics manifest in a variety of both positive and negative ways in the workplace. When managed effectively, diversity can result in increased creativity, better problem solving, and higher effectiveness; however, diversity also has the potential to create miscommunication, lower cohesion, and stress, especially when management has not placed enough importance on eliminating discrimination and building a culture of inclusion and appreciation for differences. The taxonomy described in the next section is based on social identity theory, and I provide examples of the different ways that social identity-based diversity manifests in a variety of diverse work settings.

\section{Taxonomy of Workplace Diversity}

The process of building the taxonomy began with a review of the literature to identify the major constructs that define the operations of diverse workforces. This review was used to develop a preliminary nomological network of the constructs that characterize diverse organizations. The following seven dimensions were identified from the literature: Identity, Values, Schemas, Communication, Organizational Justice, 
Taxonomy of Workplace Diversity 9

Diversity Climate, and Leadership. The definitions of each dimension in the taxonomy are provided in Table 1. In each section below, examples are provided of positive and negative manifestations of workplace diversity. For the inventory, items were written to reflect each of the seven dimensions of the taxonomy.

Identity. Perceived identity shapes peoples' in-group and out-group perceptions, emotions, and behaviors (Hogg \& Terry, 2000; Turner, 1981), and in the context of the workplace, both intra-group and inter-group feelings and relations are affected (Hogg \& Terry, 2000; Messick \& Mackie, 1989). While in-group perceptions are important for positive self-worth (James et al., 1994), distinctions made between in-groups and outgroups at work can bring about exclusion, discrimination and prejudice based on one's perceived social identity. Additionally, individual experiences in the workplace and their perceptions of organizational actions and policies will be affected by their identity group memberships (Mor Barak, 2011). In the workplace diversity taxonomy, Identity is defined as the extent to which one perceives, feels, and behaves as if they are included or excluded from the in-groups in a diverse work setting. Perceptions of inclusion/exclusion have been found to correlate with job satisfaction, employee well-being, organizational commitment, organizational justice, and job performance (Mor Barak \& Levin, 2002; Acquavita, Pittman, Gibbons, \& Castellanos-Brown, 2009; Mor Barak, Findler, \& Wind, 2003; Findler, Wind, \& Mor Barak, 2007; Cho \& Mor Barak, 2008). In this context, Identity encompasses the social or informal aspects of an employee feeling like he or she is a complete part of the organization, department or work group.

For example, the Identity dimension could manifest in a workplace composed of mostly younger people. The older employees may perceive they are highly dissimilar to 
Taxonomy of Workplace Diversity 10

their co-workers due to age. The perception of being a member of the out-group (due to younger workers being the majority) will likely result in feeling that their social identity is threatened, which, in turn, is likely to lead to disengagement (Avery, McCay, \& Wilson, 2007).

Values. In the taxonomy, values are defined as the extent to which one's central guides influence his/her perceptions of appropriate identity, preferences, beliefs and behaviors in a diverse workplace. One's values may influence attitudes toward people from different backgrounds and social identity groups (Mork Barak, 2011). Because of these influences, differences in values impact organizational diversity outcomes (Harvey \& Allard, 2005; House, Hanges, Javidan, Dorfman, \& Gupta, 2004; Markus \& Kitayama, 1991). In a study that included several items that were similar to the WDI Value items, which was termed "perceived personal diversity," strong associations were found between these items and organizational justice and organizational inclusion (Caldwell, Mack, Johnson, \& Biderman, 2002).

Value dynamics can manifest negatively in a religiously diverse workplace when members of the in-group (in the U.S., this is often Christians) demonstrate intolerance for the cultural values and behavior-norm differences of people who are not Christian, the out-group members in this case. In such a workplace, conformity pressures can be strong (Cox \& Nkomo, 1986), and the benefits of diversity may not be achieved (Adler and Gunderson, 2008).

Schemas. In the workplace diversity taxonomy, Schemas are defined as the extent to which cognitive guides lead to the organization of information and the perceived 
patterns of behaviors in diverse work settings. Schemas include stereotypes, mental maps, and behavioral scripts that guide thinking and actions toward in-group and out-group members in particular situations (Cox, 2001; Dunning \& Sherman, 1997; James, Lovato \& Cropanzano, 1994; Schaller, 1991). They provide a mental framework that often provides a sense of confidence when one encounters a person from another group. This framework is commonly developed through a combination of social, cultural, and political influences that include other encounters with people of the group, popular media images, cultural norms of tolerance, partial truths from various sources, as well as contextual variables that are influenced by current events (Bar-Tal, 1997; Bar-Tal \& Labin, 2001). These perceptions are often inaccurate and offensive when applied to an individual member of a group, as well as to the group as a whole, and they are commonly used to steer expectations and serve to justify actions that may turn out to be harmful or immoral (Tavris \& Aronson, 2007).

Schemas often manifest as stereotypes, which is "a standardized, oversimplified mental picture that is held in common by members of a group" (Taylor \& Moghaddam, 1994, p.159). As Enteman (1996) states, "a stereotype imposes a rigid mold on the subject and encourages repeated mechanical usage... The person who substitutes a stereotype for careful analysis simply does not want to work harder than necessary to achieve a superficially acceptable result. (p. 9) For example, negative attitudes toward people who are lesbian, gay, bisexual or transgender (LGBT) "can be based on stereotypes, which help people make sense of the world by categorizing their past experiences" (Lubensky et al., 2004, p.209). Between 25-66 percent of gay and lesbian employees report discrimination (see reviews by Ragins, 2004; King \& Cortina, in press; 
Lubensky et al., 2004). On the other hand, Schemas can manifest positively, or at least in a neutral manner, and more recent studies have put less emphasis on the negative aspects of stereotyping-viewing it as a basic cognitive process that is not necessarily bad (Blair, 2002; Taylor \& Moghaddam, 1994). One way this may play out in organizations is when managers and co-workers use the schema that an expatriate has certain different experiences and perspectives to bring to the table because they are from a different country. If organizational members use this schema to their advantage by encouraging and supporting expatriates to share their ideas (rather than trying to force them to assimilate to the host country's way of thinking), this is likely to inspire creativity and innovation within the organization. Increased creativity and innovation are important because of their potential to bring about a competitive edge in today's globalized economy.

Communication. In its most basic form, communication is the use of symbols to express meaning. Symbols can include words, tone of voice, gestures, or use of objects (Mor Barak, 2011). In today’s increasingly diverse and global work settings, communication is becoming largely cross-cultural. Communication in work settings between people of different cultures and backgrounds involves surmounting language barriers, including cultural differences in communication styles, nonverbal communication differences, language fluency and cultural fluency (Mor Barak, 2011; Harvey \& Allard, 2005). Nonverbal communication includes body language (e.g., movement, gestures, and postures) and the use of objects, such as personal adornments and the physical setting. For example, clothing is often used to signify rank, mood, occasion, and seasons. Trust and respect are often conveyed through nonverbal rather 
Taxonomy of Workplace Diversity 13

than verbal communication (Mor Barak, 2011). While language fluency and cultural fluency are related, they are not the same. The former is the mastery of linguistic skills that enables one to function much like a native speaker of the language. Cultural fluency, however, refers to the ability to "identify, understand, and apply the communicative behaviors of members of the other group... the ability to go back and forth between two cultures, to send and receive messages in a way that assures that the meanings of both the sender and the received regularly match" (Glazier, 2003; Molinsky, 2005; Scott, 1999, quoted in Mor Barak, 2011, p.206).

When individuals and team members have effective cross-cultural communication skills, the capacity to understand each other across differences and conflicting opinions increases (Alder \& Gunderson, 2008) and they are better able to navigate diverse interactions and organizational functions. On the other hand, miscommunication occurs when the original intent and message of the person transmitting the message is different from the meaning that is received by the other person, and this is more likely to occur between co-workers who are different from each other. Pekerti and Thomas (2003) examined intercultural and intracultural communication styles between two culturally different groups in New Zealand and found that interacting with members of a different culture increased the tendency to use the cultural communication style of their own culture. That is, the dominant tendency in cross-cultural communication is exaggeration of one's own cultural behaviors rather than adaptation. The authors attributed this behavior to the uncertainty and anxiety often provoked by cross-cultural interactions. In light of this finding, it is relevant for organizations to know the extent to which employees feel comfortable in communicating with co-workers from different cultures, 
Taxonomy of Workplace Diversity 14

backgrounds, and life experiences. In the workplace diversity taxonomy, Communication is defined as the extent to which language barriers, differences in communication styles, nonverbal communication, language fluency, and cultural fluency manifest in diverse work settings.

While many US organizations have a good deal of workforce diversity, European American employees are often the majority, and organizational leaders tend to be European American as well. In this way, these employees are perceived to be members of the in-group, while employees from a race or ethnicity other than European American may perceive that they are culturally separate, and thus, members of the out-group because they are outnumbered and have less power within the organization. This distinction can have an impact on the quality of communication within the organization, unless all employees have effective cross-cultural communication skills. With a welldeveloped understanding of the organization and the cultures represented within it, the capacity to understand each other across differences and conflicting opinions increases (Alder \& Gunderson, 2008). When this is the case, employees are better able to navigate diverse interactions and organizational functions, even across in-group/out-group divides or fault lines.

Organizational Justice. Previous researchers have suggested that organizational fairness and workers' justice perceptions are central to diversity management (Ely \& Thomas, 2001; Roberson \& Colquitt, 2005). For instance, when procedures are fair, it conveys the message that workers' have a common organizational identity (e.g. Brewer, 1991; Koper et al., 1993). Similarly, distributive, procedural, interpersonal and informational justice all help shape intra-, inter-, and organizational climates for diversity 
(Rupp, Bashur \& Liao, 2007; Cropanzano, Li \& James, 2007). For the purpose of this study, the Organizational Justice workplace diversity taxonomy dimension is defined as the extent to which employees perceive fairness of the distribution of resources, procedures, and interactions within a diverse organization.

Organizational Justice is also tied to the concept of inclusion/exclusion, and as such, it is likely to be highly correlated with Identity in the taxonomy. While Identity encompasses the affective experiences of perceiving inclusion/exclusion in the workplace, including feelings of isolation (Ibarra, 1995), Organizational (in)Justice, in this context, is most often reported in the form of limited access to, or exclusion from, informal social networks that provide critical information for job effectiveness and career advancement (Gray, Kurihara, Hommen, \& Feldman, 2007; McDonald, Lin, \& Ao, 2009). The Federal Glass Ceiling Commission has identified "information isolation," or the exclusion from information networks, as one of the main barriers that blocks the career advancement of women and ethnic minorities, particularly in the private sector (Federal Glass Ceiling Commission, 1995). This effect is compounded in people who have multiple identities with minority groups and/or who are women (e.g., women who are African-American, Hispanic gay men; Combs, 2003). Informational Justice is one of the four factors Colquitt (2001) found in the factor structure of the overall Organizational Justice construct.

In industries that are dominated by men, such as engineering and technology, men are members of the in-group because they are in the majority, they are oftentimes paid more, and they have been in positions of power within these industries for a long time. Women are members of the out-group because they are significantly in the minority, are 
Taxonomy of Workplace Diversity 16

often paid less, and find it difficult to break into the highest levels of leadership. Women can feel excluded and that this "good old boys club" is not fair. This power imbalance can be, and is often, accurately perceived as organizational injustice.

Diversity Climate. Many organizations have implemented diversity initiatives in order to more effectively manage diversity. The success of these efforts depends on the broader context of the organization (Rynes \& Rosen, 1995; Kossek \& Zonia, 1993), which has been termed diversity climate. Diversity climate has been defined in the literature as shared perceptions (at the organizational or team levels) of relationships among members of diverse groups and organizational (or team) norms and aspirations for such relationships (Cropanzano, Li \& James, 2007; Rotundo, Nguyen, \& Sackett, 2001). Gelfand and colleagues (2005) defined diversity climate as “employees' shared perceptions of the policies, practices, and procedures that implicitly and explicitly communicate the extent to which fostering and maintaining diversity and eliminating discrimination is a priority in the organization." In other words, diversity climate is employees' common understanding about "the way things are around here" regarding diversity (Reichers \& Schneider, 1990). Diversity climates are essentially internalized beliefs about past organizational (or team) diversity practices, and current organizational (or team) diversity attitudes, norms and policies. In the context of this study, Diversity Climate is defined as the extent to which employees share the perception that a diverse organization's policies, practices, and procedures communicate a strong priority given to fostering and maintaining diversity and inclusion.

The main characteristics of a positive diversity climate include public support of top management, supportive policies, and a high organizational priority on diversity 
(Rynes \& Rosen, 1995). The limited existing research indicates that diversity climate in organizations plays a critical role in many important organizational outcomes, such as training transfer (Rynes \& Rosen, 1995) and intention to accept a position (McKay \& Avery, 2006). Kossek, Markel, \& McHugh (2003) found some evidence that greater workgroup heterogeneity in terms of gender and race was associated with several indicators of a positive diversity climate. Other research has shown that specific human resource policies and practices, such as hiring practices that specifically consider an individual's race or ethnicity, lead to perceptions of the organization being supportive of diversity (Highhouse, Stierwalt, Bachiochi, Elder, \& Fisher, 1999; Kim \& Gelfand, 2003). McKay and Avery (2006) developed a theoretical model for how, when job seekers are on site visits, organizational and community attributes contribute to perceptions of the organization's diversity climate, which impacts subsequent job acceptance decisions. McKay et al. (2007) found that individual-level diversity climate perceptions were negatively associated with turnover intentions, and these effects were stronger for Black employees.

Social Identity Theory predicts that in a work setting in which heterosexuals are the majority, people who are LGBT may feel like members of an out-group and they may perceive that heterosexuals are members of the in-group, regarding sexual orientation. One way a positive Diversity Climate can alleviate this naturally occurring phenomenon is for managers and co-workers to provide supervisor and peer support, as well as social integration, for LGBT employees (Beck, Horan, \& Tolbert, 1980). This can result from LGBT friendly policies, as well as from the use of inclusive language (such as "partner" instead of "husband" or "girlfriend"). 
Taxonomy of Workplace Diversity 18

Leadership. Research has consistently shown that leader vision for, support of, and approach to diversity at work has a significant impact on workers' identities and motivation; on organizational justice systems and practices; on diversity climates and communications and, therefore; on individual and organizational diversity outcomes (D’Almeida, 2007; Wieland, 2004). In this study, leadership is defined as the extent to which the leader, or manager, in a diverse organization supports diversity as a priority. For example, leadership can manifest negatively in a predominantly European American/White workplace, when leaders display harsh scrutiny and criticism of members of ethnic minority groups, the out-group individuals in this case, which often leads to prejudice \& discrimination (Dworkin, Dworkin \& Chafetz, 1986; Pettigrew \& Martin, 1987).

\section{Summary of Workplace Diversity Measurement Literature}

Several instruments have been published that measure workplace diversity, inclusion-exclusion, discrimination, and prejudice: the Mor Barak Inclusion-Exclusion Scale (Mor Barak, 2005), the Diversity Perceptions Scale (Mor Barak, Cherin, \& Berkman, 1998), the Workplace Prejudice/ Discrimination Inventory (WPDI; James, Lovato, \& Cropanzano, 1994), the Attitudes Toward Diversity Scale (ATDS; Montei, Adams, \& Eggers, 1996), the Organizational Diversity Inventory (ODI; Hegarty \& Dalton, 1995), the Workforce Diversity Questionnaire (WDQ; Larkey, 1996), and the Perceived Occupational Opportunity Scale-Form B (POOS) and Perceived Occupational Discrimination Scale-Form B (PODS; Chung \& Harmon, 1999). However, with the exception of the first three measures, the conceptualization, development, and validation 
Taxonomy of Workplace Diversity 19

of these measures are in the preliminary stages of research (Burkard et al., 2002). More importantly, although these instruments cover various aspects of the domain of workplace diversity, such as inclusion-exclusion, discrimination, prejudice, workplace diversity attitudes, and certain dimensions of organizational diversity, not one of them encompasses the entire range of psychological constructs, patterns, and experiences that manifest in diverse workforces. For example, while several studies have demonstrated adequate reliability and validity for both the Mor Barak Inclusion-Exclusion Scale and the Diversity Perceptions Scale, each scale only represents three of the potential seven dimensions covered by the Workplace Diversity Inventory.

Researchers have recognized a void in these models and have called for expansion of them to include three important trends that have implications for the assessment of workplace diversity: (a) the prevalence of subtle forms of racism in the United States (e.g., modern racism [McConahay, 1986] and aversive racism [Gaertner \& Dovidio, 1986]), (b) development of theories of prejudice and discrimination that acknowledge explicit and implicit cognitive processes that are independent of one another (e.g., Devine, 1989; Greenwald \& Banaji, 1995), and (c) development of conceptualizations and accompanying measures that examine the appreciation of cultural diversity or the motivation to control prejudice reactions (e.g., Dunton \& Fazio, 1997; Miville et al., 1999).

These vital conceptual issues highlight the multidimensionality of diversity, and the above-mentioned measures do not address these theoretical developments. Burkard (2002) states that future research should assess subtle forms of racism and oppression and use the above conceptualizations to develop workplace diversity measures that are 
Taxonomy of Workplace Diversity 20

reflective of the multidimensional nature of workplace discrimination and prejudice. The proposed taxonomy addresses this articulated need, as the taxonomy is inherently multidimensional. As of yet, there is no instrument that measures the entire domain of workplace diversity, and the purpose of the WDI is to fully encompass the patterns and experiences that employees encounter in diverse organizations. The WDI responds to the need to address aversive racism and oppression by examining the seven dimensions (not only discrimination and prejudice) playing out among co-workers, immediate managers and top management.

Importantly, only one of the mentioned scales (Mor Barak's Inclusion-Exclusion Scale) does not explicitly state specific demographic categories within the items of the scale, which makes it difficult for these scales to work in cross cultural or global settings. For example, in the Diversity Perceptions Scale, six of the 16 items explicitly state one or more demographic group ("I feel that I have been treated differently here because of my race, gender, sexual orientation, religion or age;” Mor Barak, 2011). In terms of the definition of workplace diversity in a global context, the need to have flexibility in the referent identity constructs that are salient in a particular organizational context is vital. The references to certain categories, most commonly race/ethnicity and gender, make those scales less relevant in organizations outside the U.S. and/or multinational organizations, where specific categories may not be relevant in different cultural or national contexts. None of the WDI items mention any social identity category. In fact, it was developed intentionally to avoid doing so, which will be further explained in the method section. 
Taxonomy of Workplace Diversity 21

\section{Convergent and Discriminant Validity Measures}

Diversity and Workplace Prejudice/Discrimination. Because the WDI purports to measure the overall and specific dimensions of workplace diversity, a higher score on the WDI would provide evidence that organizational leaders are effectively managing diversity. If an organization scores highly on the Workplace Prejudice/Discrimination Inventory (WPDI), this would indicate that there is a certain level of prejudice and discrimination taking place, and consequently, that diversity is not being managed effectively. Therefore, I expect the WDI to be negatively and significantly related to the WPDI. While I expect a strong and negative correlation, I also expect that the WDI will measure a more broad scope of workplace dynamics than the WPDI because the purpose of the WDI is to measure all of the psychological dimensions of diversity that play out in the workplace (e.g., Communication, Values, Schemas, Identity), and not only prejudice and discrimination.

Diversity and Colquitt's Organizational Justice. Recent studies (e.g., Roberson \& Colquitt, 2005) have indicated that organizational justice and organizational diversity have important overlaps, including the impact of team member diversity on the formation of perceptions of justice due to potential difficulties in communication and the potential for the creation of fault lines in teams (Lau \& Murnighan, 1998). Therefore, Colquitt's measure of Organizational Justice is expected to correlate positively and significantly with the WDI.

Diversity and Negative Affect. To demonstrate evidence of discriminant validity, I included a measure of Negative Affect, hoping to find that the correlation between scores on the WDI and Negative Affect are negative, low, and nonsignificant. If this is the case, 
Taxonomy of Workplace Diversity 22

it will provide evidence to assert that low scores on the WDI are not simply due to people who are high in Negative Affect. That is, a negative evaluation of one's workplace is not simply due to that person's tendency to complain and/or to be generally pessimistic.

Diversity and Safety Climate. A measure of Safety Climate was included in an attempt to demonstrate that the WDI measures a construct that is more than just a measure of overall climate. However, included in the WDI is a measure of diversity climate, since it is one of the dimensions of the taxonomy. Therefore, while the WDI is designed to measure a broader construct than diversity climate, the two measures, the WDI and Safety Climate, are expected to at least moderately positively and significantly correlate with each other. While they are expected to correlate, I hope to demonstrate that climate measures differentiate from one another. At the same time, Safety Climate may correlate moderately with the WDI due in part to the increased level of effective communication that positive workplace diversity has the potential to create, which may in turn increase collaboration and team work, so that people tend to operate in a safer manner, resulting in an higher perceived level of Safety Climate.

\section{Workplace Diversity Taxonomy Construct Model}

In Figure 2, I present a model that provides a visual depiction of how the taxonomy could be tested for validity. On the left side of the graph, a number of possible influences on workplace diversity are listed, including the individual, organizational, and contextual factors that make an impact one's experiences within diverse work settings. In the middle of the graph, the dimensions of the workplace diversity taxonomy are listed as the ways in which employees experience and perceive diversity at work. Finally, on the 
Taxonomy of Workplace Diversity 23

right side, are the outcomes that are expected to be predicted by the dimensions of the taxonomy, including measures that were not included as a part of this study.

\section{Preliminary Research on a Model of Workplace Diversity}

Preliminary research explored the extent to which empirical support based on qualitative data could be found to verify the existence of the seven workplace diversity dimensions suggested by the literature and discussed above. This was accomplished through review and content analysis of approximately 100 critical incidents that described real-world examples of the dynamics that arose in diverse work environments. This effort supported the seven-dimension taxonomy of workplace diversity (Taylor \& James, 2010).

Participants were recruited from two different sections of a "Diversity in the Workplace" course at a major U.S. University. The 41 students ( 24 women and 17 men) were all employed at least part-time, and many were employed full-time. To test for the existence of the seven proposed constructs that characterize diverse organizations, data for this study were gathered through content analysis of 102 critical incidents. Students interviewed workers in diverse U.S.-based and international workplaces to collect critical incidents. Each student interviewed two or three different employees (yielding 102 interviewees), asking each person one of the following questions: 1) What is the most important diversity issue you have encountered in the workplace? 2) What is an experience you have had at work where the focus of the incident was a global or crossnational issue? 3) Describe an incident in which cross-cultural communication was the most important feature of an event you encountered at work. 
Taxonomy of Workplace Diversity 24

Two industrial-organizational psychology graduate students read each of the critical incidents and identified those that accurately responded to the above questions. Of the102 incidents examined, 24 were eliminated because the content did not adequately respond to the questions, resulting in an overall number of 78 critical incidents. Over 25 industries were represented, and the top three industries were 1) Food Services 2) Healthcare, 3) Education Armed Forces, and Finance (tied for third).

Using the seven dimensions of diversity culled from the literature review as a starting point, a mix of undergraduate and graduate psychology students were thoroughly trained in the definitions of the constructs and how to rate for the presence of the seven dimensions in each interview. They independently read the critical incidents and rated the representation of each dimension in each one using a 7-point Likert-type scale (1 indicating not represented and 7 indicating strongly represented). They then met to discuss their preliminary ratings and make refinements. Although the seven dimensions provided a starting point for the taxonomy, they were told that there it was possibility that more dimensions could arise from the critical incidents or that one or more of the initial dimensions may not be present in the critical incidents.

However, the research assistants found that all seven a priori constructs, and only those seven, captured the work-relevant diversity dynamics in the 78 incidents. The kappa coefficients were reasonable, ranging from good $(.60<$ Kappa $<.75)$ to fair $(.40<$ Kappa $<.60$; Fleiss, 1981).

Critical Incident Technique. The preliminary research on the workplace diversity taxonomy described above employed the Critical Incident Technique (CIT), which is a 
Taxonomy of Workplace Diversity 25

qualitative research method first developed and articulated by Flanagan (1954) and still widely used today. The technique has evolved beyond its original use as a task analysis tool into the realm of a qualitative exploratory and investigative tool used for psychological constructs and experiences (Chell, 1998; Woolsey, 1986). The distinctive features of the CIT include 1) a focus on critical events that help promote or detract from the experience of a particular situation, 2) data collection primarily via interviews, and 3) data analysis conducted by developing a frame of reference and forming categories that emerge from the data (Butterfield et al., 2005).

Flanagan asserted that CIT "does not consist of a single rigid set of rules governing such data collection. Rather it should be thought of as a flexible set of principles that must be modified and adapted to meet the specific situation at hand" (1954, p. 335). While this flexibility accounts for the innovative use of the technique across a variety of fields, it has also brought about confusion regarding everything from the best implementation approach to the terminology used to describe the technique (Butterfield et al., 2005). However, the flexibility of the technique has demonstrated its value in that it has been used as both a foundational or exploratory tool in the early stages of research and as a helpful technique in building theories or models (Woolsey 1986), which is the function CIT fulfilled in the preliminary research on the taxonomy.

Flanagan (1954) also detailed the genesis, evolution, and the procedures that have become characteristic of the CIT research method. The CIT has five major steps: (1) ascertain the general aims of the activity being studied; (2) make plans and set specifications; (3) collect the data; (4) analyze the data; and (5) interpret the data and report the results. To further explain the technique, CIT research "takes place in a natural 
Taxonomy of Workplace Diversity 26

setting; the researcher is the key instrument of data collection; data are collected as words through interviewing, participant observation, and/or qualitative open-ended questions; data analysis is done inductively; and the focus is on participants' perspectives" (Creswell, 1998, p. 16). In a CIT study, there is no set rule to determine a sufficient number of incidents. The crucial point to determining the appropriate sample size is that the incidents represent adequate coverage and description of the entire content domain of the activity in question (Butterfield et al., 2005).

Relevant Findings of Preliminary Research. The results of the content analysis of the critical incidents are presented in Figure 1, which shows the average ratings of the seven diversity dimensions ranged from 4.3 (Leadership) to 5.9 (Identity). Thus, the data demonstrate that each dimension was present in the 78 critical incidents describing workrelevant diversity, which provides evidence that each of the seven dimensions are part of the patterns that people in diverse organizations experience (Taylor \& James, 2010). The important implications of this research for designing the WDI to evaluate workplace diversity are that diversity is multidimensional and the seven dimensions appear to be present in diverse workplaces. With these findings in support of the seven-dimension taxonomy, the current study was designed to further examine the proposed model. 
Taxonomy of Workplace Diversity 27

\section{Method}

Item Development

Generating an Item Pool. Three other Industrial-Organizational Psychology graduate students (in addition to myself) were recruited to develop and review a large pool of potential items for the WDI. Four separate meetings were held for the item generation and review process. At the first meeting, I provided the definitions of the seven diversity dimensions and an overview of the research relating to each dimension and workplace diversity. The purpose of this meeting was to ensure a thorough understanding of the dimensions and their theoretical foundation, so items could be written that encompassed the entire content domain of the taxonomy. Each dimension definition was discussed, and a few example items were brainstormed in order to understand how to write items independently. Thus, deductive item generation was employed because the theoretical foundation of each dimension in the taxonomy provided the necessary information to generate the items. We also discussed the best way to develop items, focusing on established item-writing guidelines, such as ensuring that items are short, as simple as possible, and address only one issue, i.e., are not doublebarreled (Hinkin, 1998). Each person independently generated ten items per dimension, resulting in a total pool of 280 potential items.

In developing items for the WDI, each item represented workplace diversity, not just the dimension itself. To use Communication as an example, items do not reflect communication in general (e.g., being direct and open with others) but rather items that reflect communication in diverse work settings (e.g., direct and open communication at work among colleagues and supervisors). 
Taxonomy of Workplace Diversity 28

Item review. Once the initial pool of items was developed, the four IndustrialOrganizational Psychology graduate students met three more times to determine which items were consistent with the dimension definition and to ensure that they comprehensively covered the content of each dimension. Prior to the second meeting, each person independently rated the 280 items, so that, during the second meeting, the top-rated items were reviewed. Definitions of the dimensions were further discussed, including how the items measure each one. The wording of certain items was clarified for accuracy and additional items were suggested. In this way, we tried to ensure that the items in each dimension measured only one construct and that the dimensions were distinct from one another.

After the second meeting, 16-26 items per dimension remained, for a total of 143 items. Once again, each rater independently indicated their top ten items per dimension, as well as items that should be thrown out. Prior to the third meeting, I compared these ratings and brought only the top ten highest-rated items per dimension (70 items total) to the third meeting to discuss disagreements in ratings. Items were either reworded items or thrown out, resulting in an edited version of the 70 items, with 10 items representing each dimension. At the final meeting, the number of items was further cut down to six or seven items per dimension, and the final result of this process was the WDI with 47 items. These items were reviewed and content validated by dimension to ensure they covered the entire domain and that the wording was clear and simple.

Survey development. Once the items were developed, I built the online survey. It included the two measures to test convergent validity and two to test for divergent validity, as well as a questionnaire regarding relevant job characteristics (size, industry, 
Taxonomy of Workplace Diversity 29

multinational) and demographic categories (age, ethnicity/race, gender, gender identity, religion, disability, socioeconomic status, education level, and sexual orientation).

\section{Participants}

Data from all survey items were collected from a total of 209 participants who were employed a minimum of 20 hours per week currently, or within the past six months. Not more than two participants from the same organization were recruited. Participants were recruited using the snowball method, so it is not possible to calculate a response rate for subjects. Potential participants, who I met at academic conferences, via past or current international work experiences, or in the four U.S. cities in which I have lived (Sacramento, CA, San Diego, CA, Washington, DC, and Portland, OR), were sent a brief email with a summary of the study and an appeal to complete the survey if they were eligible and/or to send the link to friends and family who work at diverse organizations. Relevant email lists, such as the discussion list for the Gender and Diversity in Organizations Division of the Academy of Management, were also sent an appeal to complete the survey.

The sample demographics were as follows: $68 \%$ female $(n=141) ; 85.6 \%$ heterosexual/straight $(\mathrm{n}=179) ; 68 \%$ European American/White $(\mathrm{n}=143), 10.5 \%$ AsianAmerican/Pacific Islander $(\mathrm{n}=22), 8.6 \%$ Latino/Hispanic $(\mathrm{n}=18), 7.1 \%$ AfricanAmerican/Black $(n=15), 1.4 \%$ Native American/Alaska Native $(n=3)$, and $3.8 \%$ other (includes bi-racial; $\mathrm{n}=8) ; 48.3 \%$ Christian $(\mathrm{n}=101), 14.8 \%$ Atheist $(\mathrm{n}=31), 11 \%$ Other $(n=23), 9.6 \%$ Spiritual $(n=20), 8.6 \%$ Agnostic $(n=18)$, and less than $3 \%$ of participants were Hindu, Jewish, Buddhist, or Muslim; $64.6 \%$ of participants made an 
Taxonomy of Workplace Diversity 30

annual salary including bonuses and commissions under $\$ 60,000(\mathrm{n}=135), 21 \%$ made between $\$ 60,001$ and $\$ 100,000$ annually, and $11.1 \%$ made between $\$ 100,001$ and $\$ 200,000$ annually; 5.3\% report having a long-lasting disability $(\mathrm{n}=11)$, while $92.3 \%$ report not having one $(n=193) ; 27.3 \%$ have a 4 -year college degree as the highest level of education completed $(n=57), 23.4 \%$ have a Master's degree $(n=49), 18.7 \%$ have a Doctoral degree $(n=39), 15.3 \%$ completed some college $(n=32), 6.7 \%$ have a professional degree (e.g., MD, JD; $n=14), 5.3 \%$ have a 2 -year college degree $(n=11)$, $2.9 \%$ completed high school or obtained a GED $(n=6)$, and $0.5 \%$ of participants had less than a high school education $(\mathrm{n}=1)$. The mean age was 35.74 years $(\mathrm{SD}=12.22$; range $=$ $16-68$ years).

The evidence reported above that many demographic categories were present in the sample for this study helps answer a call from diversity experts for researchers to diversify their samples and focus on working adults in order to provide a true representation of the potential range of diversity experiences in the workplace (Burkard et al., 2002).

The organizations represented in the sample span a wide range of industries, sectors, and sizes. Participants represented 20 different industries, and the top three industries included Education Services $(\mathrm{n}=54)$, Health Care and Social Assistance $(\mathrm{n}=$ 38), and Professional, Scientific and Technical services $(n=20)$. All Industries represented are reported in Table 2. Of the over 200 organizations represented, 68 (32.5\%) were multinational, and 25 (11.9\%) were based in countries outside the U.S.A; $107(51 \%)$ were from the public sector, $62(30 \%)$ were private, and $39(19 \%)$ were nonprofits or NGOs. Regarding organizational size, 50 (24\%) had 0-50 employees, 27 
Taxonomy of Workplace Diversity 31

(12.9\%) had 51-100 employees, 51 (24.4\%) had 101-999 employees, and 79 (38\%) had more than 1,000 employees. In terms of organizational diversity, $42(20.1 \%)$ of participants reported their organization was "Very Diverse," $44(21.1 \%)$ reported it was “Diverse," 83 (39.7\%) indicated it was "Somewhat Diverse," 34 (16.3\%) described it was "Not Diverse," and 3 (1.4\%) participants were "Not Sure." The results of participantreported organizational diversity were promising, since my intention was to survey diverse organizations. In addition, the fact that over $80 \%$ of participants indicated their organizations are either "Very Diverse," "Diverse" or "Somewhat Diverse" provides evidence for the prevalence of diversity in today's workforce. Participants indicated that the top three areas in which their organizations are diverse include age, race/ethnicity and gender. 191 (94.1\% of) participants indicated their preferred language was English. Other languages indicated by participants were Spanish (8; 3.8\%), French (3; 1.4\%), Tamil (2; $1.0 \%)$, Dutch $(1 ; 0.5 \%)$, Chinese $(1 ; 0.5 \%)$, and a Native language $(1 ; 0.5 \%)$.

\section{Measures}

Demographic Background. A demographic questionnaire was included that asked about participants' ethnicity, language, gender, age, sexual orientation, faith/religion, socioeconomic status, disability, education, job level, and about the participants' organization size, sector, industry, country of origin, and whether or not it was a multinational firm.

WDI Diversity Taxonomy. The WDI examines employees' perceptions about diversity in the organization. The measure focuses on perceptions because research has found that employees' behavior is often driven by perceptions of reality, even if their 
Taxonomy of Workplace Diversity 32

beliefs are incorrect (e.g., Eisenberger, Fasolo, \& Davis-LaMastro, 1990). The WDI includes 47 items with seven dimensions: Identity, Values, Schemas, Communication, Diversity Climate, Organizational Justice and Leadership. Items evaluate a person's perceptions in relation to five different system levels: individual, work group, supervisor, higher management, and organization. Participants completed the scale described above and shown in Appendix A by indicating their level of agreement with each item using a 7-point Likert-type response scale with anchors of $1=$ strongly disagree and $7=$ strongly agree. Higher scores on the WDI reflect more positive perceptions of workplace diversity. Negatively phrased questions were reverse-scored, so higher ratings reflect more positive diversity dynamics.

The instructions provided for the instrument were developed intentionally to encourage participants to think about diversity on a wide range of demographic categories, and those that are given as example are offered for clarity only (see Appendix A).

Self-rated Primary Workplace Identities. The survey also included questions asking participants to rank the importance of different social groups or demographic categories to which they belong. The main purpose of these questions is for researchers and/or practitioners to be able to tease out the specific aspects of diversity that are important to employees. The ranking question asks, "Based on your responses, please rank the most important aspect of your identity that impacts your interactions with coworkers." The next question asks participants to rank the second most important aspect as well. The instrument also includes two questions regarding the organization's level of diversity: 1) How diverse is your organization across all major areas of diversity? 2) 
Taxonomy of Workplace Diversity 33

Name the top three (3) areas in which it is diverse. An overall qualitative question about current workplace diversity experience is also included: "What do you think about the way your organization handles diversity?"

Workplace Prejudice/Discrimination. The Workplace Prejudice/Discrimination Inventory (WPDI) developed by James, Lovano and Cropanzano (1994) is intended to measure prejudice, discrimination, bias, and stereotyping in the same organization for which participants respond to the WDI. This 15-item inventory (each with a 7-point Likert-type response scale with anchors of $1=$ strongly disagree and $7=$ strongly agree) has the strengths of its conceptual grounding in Social Identity Theory and its brevity, which allows for easy administration and interpretation (Burkard et al., 2002).

Cronbach's alphas from past studies are high $(\alpha=.93)$, factor analyses of the WPDI suggest moderate evidence for construct validity, and the evidence of criterion-related validity is promising (e.g., James, Lovano and Cropanzano, 1994). The WPDI is included as Appendix B.

Colquitt's Organizational Justice. Colquitt (2001) developed a 20-item measure of organizational justice and demonstrated validity evidence for the scale. It is an indirect measure, in that it assesses fairness criteria, such as consistency, lack of bias, and adequate explanation. Colquitt chose an indirect measure in order to more easily tie the dimensions of organizational justice to important outcomes in the workplace. All items use a 5-point Likert-type response scale with anchors of $1=$ to a small extent and $5=$ to $a$ large extent. Cronbach's alphas from past studies range from .84 to .96 (Judge \& Colquitt, 2004). Colquitt's Organizational Justice items are included as Appendix C. 
Taxonomy of Workplace Diversity 34

Negative Affect. In 1988, Watson, Clark and Tellegan developed the Positive and Negative Affect Schedule (PANAS), which consists of two 10-item scales for PA and NA, respectively. I used only the 10-item Negative Affect scale. All items included a seven-point Likert-type response scale with anchors of $1=$ not at all and $7=$ all the time, to indicate how often one has felt a certain emotion during the past week. Cronbach's alphas from past studies are high, generally ranging from .83 to .90 (Watson \& Clark, 1999). The negative affect items are included as Appendix D.

Safety Climate. The measure of Organization-level Safety Climate developed by Zohar and Luria (2005) was also given to participants. Sixteen items assess perceptions of safety, including three components as a part of one global safety climate factor: 1) Active Practices (Monitoring-Controlling), 2) Proactive Practices (Instructing-Guiding), and 3) Declarative Practices (Declaring-Informing). All items used a seven-point Likerttype response scale with anchors of $1=$ strongly disagree and $7=$ strongly agree . Example items include the following: "Management is concerned for the safety of employees," and "There is open communication about safety issues within this workplace." Cronbach's alphas for this scale was .92 (Zohar \& Luria, 2005). The Safety Climate items are included as Appendix E.

\section{Data analyses}

To initially evaluate the WDI, I computed descriptive statistics and reliability estimates for each of the expected seven dimensions. To test the validity of the WDI, I used an eleven-step process, which included both confirmatory and principle components 
Taxonomy of Workplace Diversity 35

factor analyses on the full seven-dimension model, individual dimensions, and simpler models to examine the underlying factor structure of the data. 
Taxonomy of Workplace Diversity 36

\section{Results}

An overview of the eleven-step process follows. First, I conducted an Item Analysis, calculating Cronbach's alpha for each dimension and examining the Corrected Item-Total Correlation for each item. Next, I conducted a fourteen-factor CFA, using all of the WDI items and scales of validity. Because this model did not converge, I examined the structure of the WDI and validity scales separately. Since the seven-factor model for the WDI did not fit the data well, I conducted a CFA on each dimension to test for unidimensionality. Because most of the dimensions had excellent model fit once one to three items were deleted, except the leadership dimension, I conducted an EFA on only the Leadership dimension. The Principle Components analysis revealed two factors, with items that seemed likely to load on to the Organizational Justice and Diversity Climate dimensions of the workplace diversity taxonomy. To test this and the rest of the items, I ran an EFA with 34 WDI items that demonstrated good inter-item correlations and strong unidimensionality. Using the results of the EFA and after checking to ensure the alphas were not decreased to unacceptable levels, I was able to further reduce the number of items of the WDI to 24 and conducted a six-factor CFA on these items in their respective dimensions. Next, I tested three simpler models to see if they were a better fit to the data. Finally, a second order CFA was conducted.

Testing and Reducing the WDI

Item Analysis. To analyze the individual items, I first calculated Cronbach's alpha for each dimension using all items and examined the Corrected Item-Total Correlation and "Cronbach's alpha if item Deleted" for each item (see Table 3a-g). Cronbach's 
Taxonomy of Workplace Diversity 37

alpha's ranged from .62 (Schemas) to .84 (Leadership). By examining the Item

Discrimination Index, it was clear that deleting one to two items per dimension would increase the alpha values for each dimension to acceptable levels for research.

14-factor Confirmatory Factor Analysis. An initial confirmatory factor analysis was conducted using AMOS to test for model fit using all items and all scales, a 14-factor model, including seven dimensions of the WDI (allowed to correlate), four dimensions of Colquitt's Organizational Justice, one dimension of the WPDI, one dimension of Negative Affect, and one dimension of Safety Climate. Model fit was examined by looking at the chi-square value associated with each model, and several fit indices were calculated. The normed fit index (NFI; Bentler \& Bonett, 1980) represents the proportion of improvement in fit versus a null model in which all observed variables are treated as independent. Values greater than .90 indicate a good fit to the data. The comparative fit index (CFI; Bentler, 1990) is similar to the NFI, but less influenced by sample size. For the CFI, values greater than .95 indicate a good fit. The Tucker-Lewis index (TLI; Tucker \& Lewis, 1973) is interpreted like the NFI and CFI with the difference that it adjusts for model complexity. Values greater than .90 on the TLI indicate a good fit to the data. Finally, the root mean square error of approximation (RMSEA; Browne \& Cudeck, 1993) is a measure of the lack of fit per degree of freedom in the model. For the RMSEA, values of less than .05 indicate a good fit, while values less than .08 indicate a reasonable fit (Brown \& Cudeck, 1993; Byrne, 2001). The solution for the 14-factor model was not admissible, so not fit indices are reported for this model.

Confirmatory Factor Analysis of WDI and Validity Scales. Next, in step three, each scale was analyzed individually to examine where the problems with fit were 
Taxonomy of Workplace Diversity 38

occurring. The seven-factor model for the WDI did not fit the data well $\left(\chi^{2}(1013)=\right.$ 2246.70, $p<.00 ; \mathrm{CFI}=.78, \mathrm{RMSEA}=.08)$. Except for Colquitt's Organizational Justice scale, the validity scales did not fit the model well (see Table 4): Colquitt's Organizational Justice, $\chi^{2}(164)=416.78, p<.00, \mathrm{CFI}=.95, \mathrm{NFI}=.93, \mathrm{RMSEA}=.09$; Workplace Prejudice/Discrimination Inventory (WPDI), $\chi^{2}(90)=412.24, p<.00, \mathrm{CFI}=$ $.81, \mathrm{NFI}=.77, \mathrm{RMSEA}=.31$; Negative Affect, $\chi^{2}(35)=372.42, p<.00, \mathrm{CFI}=.70, \mathrm{NFI}$ $=.69, \mathrm{RMSEA}=.22 ;$ Safety Climate, $\chi^{2}(104)=780.88, p<.00, \mathrm{CFI}=.80, \mathrm{NFI}=.71$, RMSEA $=.18$.

Unidimenational Confirmatory Factor Analyses for the WDI Dimensions. In step four, I conducted a confirmatory factor analysis on each of the seven WDI dimensions to determine unidimensionality and to see which items were pulling the model fit down (see Table 5). As Table 6 indicates, a unidimensional model fit the data well for six of the seven dimensions after one to three items per dimension were deleted.

Principle Component Analysis of Leadership Dimension. Because a

unidimensional model for the Leadership dimension did not fit the data well $\left(\chi^{2}(14)=\right.$ $124.66, p<.00, \mathrm{CFI}=.84, \mathrm{NFI}=.79, \mathrm{RMSEA}=.19)$, in step five, a Principle Components factor analysis was conducted on the ratings for the seven items that of dimension. This yielded two main factors that accounted for $67.64 \%$ of the variance in item scores. All seven items loaded positively and substantially (all weights above .50) on these two factors. The factors corresponded to two of the other (i.e., non-Leadership) dimensions in the initially-hypothesized 7-factor taxonomy: Organizational Justice and Diversity Climate. The three items that loaded onto the WDI Organizational Justice dimension were the following: 1) My manager creates a comfortable working 
Taxonomy of Workplace Diversity 39

environment for all types of people (.85), 2) My boss discriminates against certain groups of employees regardless of their performance ( $\mathrm{R} ; .88)$, and 3) My manager is skilled at handling the diversity in my workplace (.68). The three items that loaded onto the Diversity Climate dimension of the taxonomy were the following: 1) Leaders here connect diversity to the organization's mission and vision (.96), 2) Senior management is committed to diversity in my organization (.77), and 3) My manager focuses on continuous learning about diversity (.83). Thus, in subsequent analyses, I collapsed the Leadership items with the dimension (Diversity Climate or Organizational Justice) to which each corresponded.

Principle Components Analysis of WDI Items. To further examine the WDI items, in step six, a Principle Components factor analysis was conducted on the ratings for 34 items that represented all seven dimensions to see if I could further reduce the number of items, while not compromising the alphas too drastically. Direct oblimin factor rotation was used, since the dimensions were theorized to be correlated, i.e., part of an interactive pattern of psychological constructs that manifest in diverse workplaces. This yielded seven main factors with Eigenvalues over 1.00, which accounted for $63.63 \%$ of the variance in item scores. The rotation converged in 30 iterations. I examined the Pattern Matrix for items to load onto factors with values of .45 or higher on only one dimension. Items were deleted that loaded on more than one dimension with values of .3 or higher and/or that did not have a high enough factor loading (i.e., above .45). Three of the four items that represented the Leadership dimension loaded onto Diversity Climate with factor loadings of .77 or higher, while three different Leadership items loaded onto the WDI Organizational Justice with factor loadings of .75 or higher. 
Taxonomy of Workplace Diversity 40

Calculating Cronbach's Alpha on the dimensions of the WDI-24. After using the

above methods, the WDI was modified and the number of items was reduced from 47 to

24 items, with three to five items for each of six dimensions. A composite index was then calculated for each WDI-24 dimension by combining the items loading on each factor. Internal consistency reliabilities were computed for each dimension to ensure they were not cut too drastically (see Table 7). The Cronbach's alphas ranged from .91 for

Diversity Climate to .67 for Communication, with means of $4.26(S D=1.46)$ to 5.91 ( $S D$ $=0.91)$, respectively. The alpha levels for four of the six dimensions indicate a high degree of internal consistency for the items that compose each of those dimensions, and they were within acceptable limits (Nunnally \& Bernstein, 1994). However, the internal consistencies of Schemas $(\alpha=.68)$ and Communication $(\alpha=.67)$ were just below the standard rule of thumb of .70 for acceptable internal consistency for research.

Principle Components Factor Analysis of the WDI-24. In step eight, the Principle Components analysis of the final 24 WDI items (WDI-24) demonstrated that there were six factors with Eigenvalues over 1.00, which accounted for $63.33 \%$ of the variance. An examination of the scree plot also revealed six factors. The factor loadings from the Principle Components analysis are presented in Table 8.

Confirmatory Factor Analysis of the WDI-24.To apply a more rigorous test of the six-dimension model and to test alternative models, in step nine, I conducted maximum likelihood confirmatory factor analysis with the responses to 24 WDI items using AMOS. The factors were allowed to correlate, as in the Principle Components factor analysis. The six-factor model was tested, and the final 24 WDI items and their standard regression weights are presented in Table 9, and correlations between the six factors are reported in 
Taxonomy of Workplace Diversity 41

Table 10. With all six WDI dimensions, the fit indices indicated adequate to good fit $\left(\chi^{2}\right.$ $(237)=346.01, p<.00, C F I=.94, T L I=.93, N F I=.84, R M S E A=.047)$.

As Table 9 demonstrates, all items had standardized regression weights of .50 or higher, except two items in the Schemas dimension. Table 8, which lists the factor loadings from the principle components factor analysis of the WDI-24, reveals where the issues with structural validity may rest. The items representing Communication cross loaded on both Values and Identity. In addition, there was one dimension (dimension 5) in which only two items from different dimensions loaded at .40 or higher, so it was not possible to identify that dimension.

Since there were 15 cases with missing data, I was not able to examine the standardized residual covariance matrix, nor the GFI fit index.

Testing Simpler Models. In step ten, I tested simpler models of the WDI. Table 11 indicates that the six-factor model yielded improvement over the one-, two-, and fivefactor models. In addition, most of the fit indices for the six-factor model were above the .90 rule of thumb for adequate fit, and only this model had a "good" RMSEA value (.047;Bentler, 1990; Byrne, 2001). Therefore, I concluded that the six-factor solution should be retained for additional validation work.

Testing for Second Order Factor Structure. Because the dimensions of the WDI24 were theorized to correlate, and the empirical evidence provides support that this is the case, I tested a second order factor structure to see if the six dimensions were tied to a global diversity latent factor. The test results demonstrated adequate fit $\left(\chi^{2}(246)=\right.$ $390.12, p<.00, C F I=.92, T L I=.91, N F I=.82, R M S E A=.05)$. 
Taxonomy of Workplace Diversity 42

Testing the Validity of the WDI-24

Bivariate correlations. Correlations of each WDI dimension and the validity scales are reported in Table 12. Correlations of the summed WDI-24 scores with composites of the four measures of validity were computed to test for convergent and discriminant validity, i.e., to demonstrate the inventory is related to two theoretically relevant constructs and not related to non-relevant constructs (James et al., 1994). These composite scores included the overall WDI-24 and the four separate measures of validity, including Colquitt's Organizational Justice, Workplace Prejudice and Discrimination, Negative Affect, and Safety Climate (see Table 13).

The hypothesized relationships between the WDI-24 and the measures of convergent validity were supported. Colquitt's Organizational Justice positively and significantly correlated with the WDI-24 $(r=.59, p<.01)$. The Workplace Prejudice and Discrimination Inventory (WPDI) negatively and significantly correlated with the WDI$24(r=-.70, p<.01$; with higher scores on the WPDI indicating more prejudice/discrimination in the workplace). Negative Affect (NA) negatively and significantly correlated with the WDI-24 $(r=-.39, p<.01-$ i.e., higher NA scores were associated with lower WDI scores); and Safety Climate was positively and significantly correlated with the WDI-24 $(r=.52, p<.01)$.

Differences by demographic category on the overall WDI-24. I analyzed how certain demographic categories predict scores on the overall WDI-24. The descriptive statistics of the differences by ethnicity and sexual orientation are presented in Table 14. It seems that White participants and Latino participants responded similarly on the overall WDI-24 $(M=5.15, S D=.73$ and $M=5.11, S D=.77$, respectively $)$. However, 
there are notable differences in the overall WDI-24 scores are between Asians/Pacific Islanders, who had the highest $(M=5.34, S D=.84)$, and African-Americans/Blacks, who had the lowest $(M=4.89, S D=.87)$. There was no substantial difference in the overall WDI-24 mean score for participants who identified as Lesbian, Gay, Bisexual, Transgender or Queer $(n=29, M=5.14, \mathrm{SD}=.63)$ compared to those from participants who identified as heterosexual or straight $(n=179, M=5.17, S D=.76)$.

Differences by demographic category on the dimensions of the WDI-24. A multivariate analysis of variance (MANOVA) was conducted to evaluate the relationships between the six dimensions of the WDI-24 and four individual demographic categories. The independent variables were demographic categories, which included age, race/ethnicity, gender, and education. The dependent variables were the six dimensions of the WDI-24. The omnibus MANOVA was significant for at least one dimension per demographic category. There were significant differences by gender for the Values dimension of the WDI-24, $F(2)=3.46, p=.04$. There were also significant differences in the mean scores of the Diversity Climate dimension by age, $F(46)=1.72, p=.04$. Similarly, when considering ethnicity, significant differences were found in the mean scores of the Identity dimension, $F(5)=2.60, p=.04$. Finally, significant differences were found in the Values dimension by education, $F(6)=2.38, p<.05$.

Regression. Because respondents indicated that age, gender, and race/ethnicity were the most important aspects of their identity that impact interactions with coworkers, these variables were theorized to be potential precursors of positive or negative experiences in diverse workplaces. Due to the fact that the sample was highly educated, I also included education as a predictor in a regression analysis, along with the above 
demographics (age, ethnicity/race, gender), in predicting scores on the overall WDI-24, controlling for organizational diversity, sector, size, and whether or not the organization was multinational. Organizational diversity significantly predicted scores on the overall WDI-24 $(\beta=.45, t=6.17, p<.00)$. Education was also a significant predictor $(\beta=.18, t$ $=2.40, p=.02$ ). No other constructs were significant.

Overall, the results of the factor analyses, the bivariate correlations, and the regression analysis provide some promising evidence for the validity of the WDI.

Qualitative responses. From the qualitative responses $(\mathrm{N}=184)$, four main themes emerged: Positive (81), Negative (33), Ambivalent (55), and Neutral (7). A multivariate analysis of variance (MANOVA) was conducted to evaluate the relationships between the six dimensions of the WDI-24 and the four themes that emerged from the qualitative data. The independent variables, themes, had four levels (positive, neutral, ambivalent, negative). The dependent variables were the six dimensions of the WDI-24. The omnibus MANOVA was significant for all dimensions of the taxonomy (Diversity Climate, $\left(F(3)=29.00, p<.00\right.$, partial $\eta^{2}=.34$;

Organizational Justice, $F(3)=28.35, p<.00$, partial $\eta^{2}=.33$; Identity, $F(3)=14.68, p<$ .00, partial $\eta^{2}=.21 ;$ Schemas, $F(3)=7.99, p<.00$, partial $\eta^{2}=.12 ;$ Communication, $F$ (3) $=4.62, p<.00$, partial $\left.\eta^{2}=.08\right)$, except Values. These results indicate that respondents who provided the most positive qualitative diversity evaluations reported the highest scores on the WDI-24. For example, regarding Diversity Climate, respondents who provided a theme 1 [positive] response, had substantially higher scores $(M=4.94$, $\mathrm{SD}=1.18$ ) than the average WDI scores of the respondents who provided a theme 4 
Taxonomy of Workplace Diversity 45

[negative] response $(\mathrm{M}=2.62, \mathrm{SD}=1.21)$. This pattern held true for all WDI-24

dimensions, except Values.

Bonferroni post hoc tests demonstrated that most of the significant differences were found between themes 1 and 4, and between themes 1 and 3 . The largest mean differences were between theme 1 and theme 4 .

An example of a Positive response is: "Our organization handles diversity very well. It branches out into the community and provide programs and services helpful to all walks of life." A response that exemplifies the Negative responses is, "They don't really handle diversity because they try to avoid it." An example of the Neutral theme is, "I have no real opinion. It is what it is."

For the Ambivalent theme, there were five main sub-themes: General Ambivalence (16); Good Intentions, Bad Initiatives (4); Good in some Demographic Categories, Bad in Others (12); Pays Lip-Service, but Lacks Follow-through (14); Good on one Organizational Level, Bad on Others (9). The following response demonstrates the General Ambivalence subtheme, “They don't necessarily promote diversity, but they do make sure that diversity is respected, and discrimination is not tolerated." An example of the Good intentions, Bad Initiatives subtheme is, "Intentions are excellent and there is a commitment by leadership to promote diversity. However, diversity initiatives often are not very effective... (they) feel forced and not very well thought out. The organization needs more tools to actually have an authentic diversity. Often folks from minority groups at our organization feel like token representatives, rather than integrated parts of the core organization." A response that exemplifies the Good in some Demographic Categories, Bad in Others subtheme is, "Overall, it is a major priority. That said, the 
Taxonomy of Workplace Diversity 46

higher up the ladder you go the fewer women you find. Also, as a young professional, you are often seen as not having any experience compared to those with much more and sometimes your ideas might be dismissed because of your age. On the whole though, it is very inclusive of different types of diversity, especially ethnic diversity." An example of the Pays Lip-Service, but Lacks Follow-through sub-theme is, "(While) we do a good job at defining the issue, we do not do as good a job at holding people accountable for the leadership behaviors we desire." Finally, an example of the Good on one Organizational Level, Bad on Others subtheme is "It is handled very well in terms of the larger organization (Board of Directors, stakeholders, etc.) but not seen as quite as much of a priority in dealing with staff."

\section{Exploratory Analyses}

To further investigate the dimensions of the workplace diversity taxonomy, the following exploratory analyses were conducted.

Testing Ethnicity as a Frame of Reference. To test the possibility that ethnicity/race may be a built-in frame of reference for workplace diversity, an analysis of variance was conducted to evaluate the relationship between the dimensions of the WDI and ethnicity/race. The independent variable, ethnicity, had six levels (White, Black, Asian-American, Latino, Native, and Other). The dependent variables were the six WDI dimensions, with higher scores indicating more positive diversity dynamics. Significant differences were found on two of the six WDI dimensions due to ethnicity, which were Identity, $F(5)=3.18, p<.01, \eta^{2}=.07$ and Organizational Justice, $F(5)=2.83, p<.02, \eta^{2}$ 
$=.07$. However, Bonferroni post-hoc analyses revealed no significant differences between the ethnic groups represented.

Regression of Safety Climate and WDI-24. In order to further explore the relationship of the WDI-24 dimensions and Safety Climate, a regression analysis was conducted to evaluate how well scores on Safety Climate could be predicted by the workplace diversity taxonomy dimensions and Colquitt's measure of Organizational Justice, controlling for organizational diversity, size, sector, and whether or not the organization was multinational. The results indicated that two of the six WDI dimensions, Diversity Climate $(\beta=.26, \mathrm{t}=3.19, p<.01)$ and Identity $(\beta=.34, t=3.64, p<.00)$, positively and significantly predicted Safety Climate scores, which indicates that for every point increase in the scores on these dimensions, the score on Safety Climate increases by about one-fourth (Diversity Climate) to one-third (Identity). The other constructs included were not significant predictors. Approximately $42 \%$ of the variance in Safety Climate scores was accounted for by its linear relationship with the included constructs.

Regression of WPDI and WDI-24. A regression analysis was performed to evaluate how well scores on the WPDI could be predicted by scores on each WDI dimension, controlling for organizational diversity, size, sector, and whether or not the organization was multinational. The results demonstrate that two of the six dimensions were found to significantly predict scores on the WPDI: Organizational Justice $(\beta=-.58$, $t=-6.52, p<.00)$; and Schemas $(\beta=-.14, t=-2.28, p=.02)$. Communication approached significance $(\beta=-.22, t=-3.70, p=.05)$. The other included constructs were not 
significant predictors. Approximately $61 \%$ of the variance in WPDI scores was accounted for by its linear relationship with the included constructs.

Analysis of Variance of Communication in Multinationals vs. Domestic Organizations. A one-way analysis of variance was conducted to evaluate the relationship between the Communication dimension of the WDI and whether an organization was multinational or domestic. The independent variable, organization classification, had two levels (multinational and domestic). The dependent variable was the composite score of the Communication dimension with higher scores indicating more positive diversity dynamics. The ANOVA was not significant, $F(1,199)=.13, p=.72$. 
Taxonomy of Workplace Diversity 49

\section{Discussion}

Summary of Findings

Contributions to the academic study of workplace diversity. Due to the increasing influence of globalization and the stubborn persistence of discrimination based on social identity in the workplace, it is vital to gain a more complete understanding of workplace diversity. Scholars have not yet reached consensus on a definition of diversity, one that systematically defines the entire domain of diversity at work. This is in part due to the fact that no published research to date has defined workplace diversity in a systematic and operational way. In the past 20 years, 30 academic definitions of diversity have been put forward, which does not include the plethora of definitions developed within applied settings. Nor have scholars decided which scale accurately measures diversity at work. It is not possible to accurately research any topic without strong conceptual and measurement tools. This study is an important first step in articulating the specific psychological constructs that employees experience in diverse work settings, and it contributes to the academic study of workplace diversity in important ways. Although it seems reasonable that diversity is multidimensional given the wide range of constructs that have been associated with workplace diversity in the literature, this research is the first effort that has been undertaken to systematically identify the potential dimensions of diversity and to empirically examine its multidimensionality. In doing so, it offers a conceptual framework and an operational definition, the Workplace Diversity Taxonomy, that helps expand our understanding and ability to measure the constructs present in increasingly diverse work settings, which fills an articulated gap in the workplace diversity literature (Burkard et al., 2002). This taxonomy has been created in an attempt 
Taxonomy of Workplace Diversity 50

to classify the entire domain of workplace diversity in order to clarify and detail the essential patterns of experience found in diverse work settings. In applying the taxonomy, an instrument, the Workplace Diversity Inventory, has been developed and promising evidence of validity has been found. The WDI-24 includes but goes beyond two common measures of diversity: diversity climate and inclusion. While diversity climate and inclusion are important, they do not encompass the entire range of psychological patterns and experiences that manifest in diverse workforces.

It is also important to note that the dimensions of the WDI are correlated (the correlations range from .10 to .59), and each item has an intentionally built-in frame-ofreference for diversity at work. These two features of the scale demonstrate the additional utility that the WDI, and thus, the taxonomy, provides. Researchers cannot simply use separate, currently validated scales for each dimension of the WDI to measure workplace diversity. The dimensions are part of an interlocking pattern of experiences, and the taxonomy classifies - while the WDI measures - them as such.

Different system levels analyzed in the WDI. While the WDI-24 measures individual level perceptions of the respondents, the items in the scale refer to the following five system levels at work: individual, workgroup, supervisor, higher management, and organization, which aligns with Mor Barak's Inclusion-Exclusion Scale (Mor Barak, 2011). In building the scale, it was considered that this may impact the ability to generate structural validity for the WDI. Certain dimensions ask questions about only one of these levels, such as Values, which references only the individual level (e.g., "I value diversity in the workplace"). Other dimensions reference from one to four levels, such as Organizational Justice (e.g. "My manager creates a comfortable working 
Taxonomy of Workplace Diversity 51

environment for all types of people," which refers to the Supervisor system level, and "Certain people are denied opportunities at work because of who they are", which can refer to the supervisor, higher management, and organization system levels). For a complete listing of the system level(s) to which each item refers, see Table 9. One reason why a simpler five-factor model was tested for model fit was to see if the scale broke into five dimensions, along these organizational system levels. The CFA revealed that a sixfactor model fit the data better than the five-factor model, which provides evidence that these differences do not make a large impact on the structural validity of the WDI overall. Potential for use in applied global work settings. A further contribution of the scale is that it has the potential to be used in global work settings. Unlike most commonly used scales of workplace diversity (for an exception, see Mor Barak's [2005] Perception of Inclusion-Exclusion Scale), the WDI-24 items do not include specific reference to one or more demographic categories. The scale can reference the categories that are specific to cultural or national environments. It is not limited to using the common types of diversity in the U.S., e.g., race, gender, age. The instructions of the scale were developed with this in mind, and the instructions can be modified to include the most salient referent-identity examples for the culture or context in question.

Major results and conclusions. The major results and conclusions of this research can be summarized as follows. First, workplace diversity seems to be a multidimensional construct, as evidenced by principle components and confirmatory factor analyses of the WDI data that support a six-dimension taxonomy. The second major finding of this research is that the dimensions of the taxonomy differentially predict important workplace outcomes, such as safety climate and prejudice/discrimination. Support for this 
Taxonomy of Workplace Diversity 52

assertion was derived from an examination of the bivariate correlations of the dimensions of the WDI and the validity measures, analysis of variance, and regression analyses.

While some of the bivariate correlations of the WDI dimensions and the validity measures are suspiciously high, there is reason to infer that these may be inflated. Three of the four validity measures did not fit the data well, according to the CFA fit indices. This may be due in part to small sample size; however, the fit indices of both the unidimensional CFAs and the six-factor model of the WDI fit surprisingly well. This provides further evidence for the structural validity of the WDI. However, in previous studies, the four validity measures demonstrated adequate to good structural validity, so it is unclear why these measures did not hold up as well in this study, and it may help explain the high correlations between, for example, the WPDI and the WDI dimension of Organizational Justice $(r=-.72)$. Future research should be done to discover why these scales had such poor fit.

Strengths of the study. The composition of the sample was working adults, rather than undergraduates. The sample is diverse on many different individual demographic categories, such as age, religion/faith, and gender, as well as along different organizational characteristics, such as size, sector, level of diversity, and whether or not it was multinational. Additionally, a wide range (over 20) of industries is represented. The scores of the WDI dimensions did not differ significantly due to ethnicity among four of the six dimensions, and of the two dimensions that differed, the effect sizes were very small. A further strength is that there are multiple (4) measures of convergent and discriminant validity criteria. Finally, there is substantial convergence of the factor 
Taxonomy of Workplace Diversity 53

structure with the literature review and the preliminary qualitative study, even though some differences are present.

The qualitative responses within the survey demonstrate one more strength. Not only are mixed methods desirable in research design generally, in this case, the qualitative data provide evidence that the WDI is actually measuring how diversity is playing out within organizations. Since this study surveyed many organizations, rather than one or a few, it was not possible to aggregate the scores and follow up with qualitative research to see if the WDI score an organization received actually corresponded to the reality of how diversity manifests. However, the results of the MANOVA suggest that WDI scores actually do reflect an organization's true diversity dynamics. Those respondents who provided positive comments regarding the way their organization manages diversity had significantly higher mean WDI dimension scores than those who indicated they were negative or ambivalent about it.

Bivariate correlations of the overall WDI composite score and the measures of convergent and discriminant validity. While the correlation between Safety Climate and the overall WDI composite score was expected to be significant and positive, the fact that it correlated at $r=.52$ made it seem more a measure of convergent, rather than discriminant, validity.

However, an examination of the bivariate correlations by dimension provides a clearer picture of these relationships, and of the utility of the taxonomy dimensions themselves. 
Taxonomy of Workplace Diversity 54

Diversity Climate. Since both are measures of climate, it was expected that the Diversity Climate subscale of the workplace diversity taxonomy would correlate positively and significantly with the measure of Safety Climate, and the bivariate correlations indicated this was the case $(r=.47, p<.01)$. However, Safety Climate was included as a measure of discriminant validity, so it was slightly unexpected, though not entirely surprising, that the scales correlated at this level. The fact that the two scales did not correlate more highly provides some evidence that the two scales are different from one another. That is, this study provides evidence that the WDI Diversity Climate dimension measures more than overall climate and that climate scales differentiate from one another, at least moderately.

The WPDI was included as a measure of convergent validity, and it was expected to correlate negatively and significantly with the WDI dimensions. Its correlation with the Diversity Climate subscale provides evidence of convergent validity $(r=-.43, p<$ $.01)$.

Turning to the correlations between the subscales of the workplace diversity taxonomy themselves, the correlation between the Diversity Climate dimension and the WDI Organizational Justice dimension was positive and significant, as expected $(r=.49$, $p<.01$ ). Both dimensions include items that refer primarily to the higher system levels, such as higher management, organization, and supervisor. Of note as well is the correlation between Diversity Climate and Identity, which was also positive and significant $(r=.46, p<.01)$. Since inclusion is a common and important construct within the diversity literature, it is not surprising that Identity (defined as the extent to which one feels included or excluded in diverse work settings) is highly correlated with Diversity 
Taxonomy of Workplace Diversity 55

Climate, since it is also one of the most common constructs within the literature. In a workplace with a strong and positive climate for diversity, it makes sense that employees would tend to feel more included, and vice versa.

The results of the regression analysis demonstrated that the WDI Diversity Climate subscale significantly predicted scores on Safety Climate. This gives credence to the argument that an organization with a more positive diversity climate would be adept at creating an overall positive organizational climate, which would include developing a strong Safety Climate. The opposite would also be true. If employees perceive that the organization, through its policies, procedures and practices, places a priority on diversity and sees it as an asset, it stands to reason that employees in this environment would trust their co-workers more, despite - or possibly due to - their differences. Increased trust often leads to a stronger Safety Climate.

The results of the MANOVA on the six sub-scales of the taxonomy and the salient demographic categories (age, gender, ethnicity and education) demonstrated that age was a significant predictor of Diversity Climate. This is in alignment with current research which demonstrates that the age is one of a important demographic factor that often impacts an individual's experience within the workplace.

Organizational Justice. It was expected that the Organizational Justice subscale of the workplace diversity taxonomy would correlate positively and significantly with Colquitt's measure of Organizational Justice, and it did $(r=.63, p<.01)$. This was the highest correlation of Colquitt's measure with any of the other dimensions of the WDI, which provides evidence if the validity of the WDI Organizational Justice dimension. 
Taxonomy of Workplace Diversity 56

However, the correlation of the WDI Organizational Justice subscale and the WPDI was even higher $(r=-.72, p<.01)$. This may be due to the poor structural validity of the WPDI found in this study. Since it makes sense that an organization which scores highly on the WDI Organizational Justice dimension (i.e., that employees perceive high levels of fairness at work) would have a low occurrence of discriminatory behaviors, it was expected that the two constructs would be negatively and significantly correlated. However, at a correlation of -.72, this indicates the two are a very similar, but opposite, construct. Further research is needed to determine why this relationship is so strong.

The correlation between Safety Climate and the WDI Organizational Justice dimension $(r=.47, p<.01)$ seems to indicate that Safety Climate, intended to be a measure of discriminant validity, provides further evidence of convergent validity, especially in addition to its correlation with Diversity Climate and Identity.

The final bivariate correlation of note for the WDI Organizational Justice dimension is between it and Identity $(r=.59, p<.01)$. This relatively high correlation is in line with previous research which links identity and organizational justice through the construct of inclusion (Mor Barak, 2011).

Regarding the MANOVA on the six sub-scales of the taxonomy and the salient demographic categories (age, gender, ethnicity and education), significant differences based on ethnicity/race were found in the mean scores of the WDI Organizational Justice dimension. While the effect size was small $(\eta 2=.06)$, demonstrating that this finding may be of little practical significance, it is not unexpected. The finding that employees of different ethnicities would perceive organizational fairness differentially is consistent with the literature. Even with small sample sizes for all ethnic groups other than 
Taxonomy of Workplace Diversity 57

Whites/European Americans, this difference was detected, which provides evidence of the validity of the WDI Organizational Justice dimension. However, because the sample sizes were so small, future research may demonstrate different results.

The regression analyses on the three demographic categories participants noted as most salient aspects of their identity: age, gender, and race/ethnicity, controlling for organizational characteristics, found that ethnicity/race predicted scores on the WDI Organizational Justice dimension. While the effect size was small, as with Diversity Climate, it stands to reason that employees of different ethnicities would perceive fairness in the workplace differently.

Identity. Safety Climate correlated most highly with the Identity subscale of the workplace diversity taxonomy $(r=.51, p<.01)$, and this relationship was stronger than that of Safety Climate with the climate dimension (Diversity Climate) subscale, which was not expected. One explanation for this may be that since the items representing the Safety Climate scale refer to actions of top management, it seems to be the case that creating a strong safety climate helps employees feel more included among their coworkers. Also, the Identity dimension items include statements about how employees perceive that they are included among their co-workers and within their working group. Therefore, when employees feel like they are part of a cohesive team, they are more likely to look out for other team members, and thus, create a stronger safety climate, in line with top management actions.

As a measure of convergent validity, it was expected that the Identity dimension would negatively and significantly correlate with the WPDI, which was found to be true $(r=-.50, p<.01)$ 
Taxonomy of Workplace Diversity 58

Similarly, Colquitt's measure of Organizational Justice correlated positively and significantly with the WDI Identity dimension $(r=.53, p<.01)$, in line with my expectation as a measure of convergent validity. The fact that the only higher correlation than that of Colquitt's Organizational Justice measure and the WDI Identity dimension was with the WDI Organizational Justice dimension serves to validate the Identity dimension. That is, the high correlation between Colquitt's Organizational Justice and the WDI Identity dimension is in line with current research which demonstrates that employee perceptions of fairness are related to feeling included at work (Mor Barak, 2011). The fact that this correlation is not as high as that of the two measures of the same name (i.e., Colquitt's Organizational Justice and the WDI Organizational Justice subscale) provides further evidence to validate the Identity dimension and subscale. In addition, the WDI Identity dimension positively and significantly correlated with the Communication dimension $(r=.49, p<.01)$. This was an interesting finding, since there did not seem to be a great deal of evidence of this relationship in the literature. However, it makes sense that if one feels more a part of the one's work group, they would also communicate with their co-workers better, and that this would hold true even in the present of a high level of group diversity. A different explanation may be that if an employee has good communication skills, he or she may have an easier time identifying with other co-workers and integrating oneself into the group.

A regression analysis indicated that the Identity (in addition to Diversity Climate, as noted above) subscale of the workplace diversity taxonomy was a significant predictor of scores on Safety Climate. This helps validate this dimension because it stands to reason that an organization that makes employees feel included (i.e., receives high scores 
on the WDI Identity dimension) would be adept at creating an overall positive organizational climate, which may include developing a strong Safety Climate. The opposite would also be the same. It stands to reason that employees who feel included would trust their co-workers more, and thus, creating a stronger Safety Climate.

Similar to the WDI Organizational Justice dimension, significant differences based on ethnicity were found in the WDI Identity dimension scores. While the effect size was small $(\eta 2=.07)$, demonstrating that these findings may be of little practical significance, there may not have been enough power, due to small sample sizes for all ethnic groups other than Whites/European Americans, to detect important differences, and future research may demonstrate different results. At the same time, the finding that the effect sizes detected in this sample for the significant results were very small, in addition to the finding that four of the six dimensions had no significant differences, provides evidence that the WDI dimension scores do not seem to vary substantially based on one's ethnicity/race.

Additionally, the finding that the significant differences found based on ethnicity seem to originate in the differences in mean scores between self-identified AfricanAmericans/Black s and Asians/Pacific Islanders adds to the work of Foldes, Duehr, \& Ones (2008), who found that the greatest potential for adverse impact in personality testing exists when the groups being compared are Blacks and Asians. However, because both racial/ethnics groups have a great deal of within-group diversity, future research should examine this phenomenon further with larger sample sizes. 
Taxonomy of Workplace Diversity 60

Values. The regression analyses provide evidence that the six WDI dimension scores do not seem to vary to a great extent based on the three demographic categories participants noted as most salient aspects of their identity: age, gender, and race/ethnicity. Gender significantly predicted the Values dimension of the WDI, but the effect sizes was small (.04-.06). This provides preliminary evidence that the WDI would measure perceptions of workplace diversity roughly equally across demographic categories.

\section{Limitations}

Sample Size and Composition. One possible limitation of the study is the relatively small sample size $(\mathrm{N}=209)$ for an instrument based, originally, on seven dimensions. Having a larger sample size may result in a more accurate test of its structural validity. However, the fact that the six-dimension model fit the data well with only 209 participants provides evidence for the strength of the WDI. In addition to the small sample size, another potential limitation is that the participants were highly educated, with $42.1 \%$ having a either a Master's or Doctoral degree $(n=88)$. However, in light of the high level of education, the sample had a surprisingly minimally aboveaverage income range. Regarding the participants' religion/faith, there was an aboveaverage representation of those who would generally fall into the category "spiritual but not religious," with a surprising 31 respondents identifying as atheist (14.8\% of the sample). Additionally, the nearly $6 \%$ of respondents who indicated they have a longlasting disability $(n=11)$ falls below the U.S. average of $18 \%$ of the workforce (Bureau of Labor Statistics, 2011; USDHHS Office on Disability, 2011). One of the possible differences in the preliminary study and the current study was that immigrants were 
Taxonomy of Workplace Diversity 61

probably relatively highly represented in the participant sample of the preliminary study.

The current study did not collect data on whether or not the participants were born in the U.S. or not.

While the top three demographic categories indicated as the most important to respondents regarding their interactions with co-workers (age, race/ethnicity, gender) were not significant predictors of the overall WDI composite scores, education and organizational diversity were found to be significant predictors. Organizational diversity was included as a control variable. The fact that education was a significant predictor makes the limitation of the over-representation of participants with graduate degrees more notable.

Self-report Measure. One limitation of the WDI itself is that it is a self-report measure, the limits of which have long been recognized in psychology in the measurement of prejudice, discrimination and workplace diversity (Crosby et al., 1980; Dunton \& Fazio, 1997; Ponterotto \& Casas, 1991; Sniderman \& Tetlock, 1986). The accuracy of a self-report measure relies on the extent to which the respondents' perceptions and insights reflect the actual phenomenon of interest. For example, in measuring prejudice, it is likely that participants would present themselves in an overly virtuous and unprejudiced manner because self-report measures are particularly susceptible to socially desirable responding. Socially desirable responding refers to the tendency to base item responses on social pressures, rather than how the individual would score on that construct if other methods were used (Stricker, 1963; Zerbe \& Paulhus, 1987). Individuals responding in this manner will favor socially approved behaviors and will deny association with behaviors or opinions that are less socially acceptable, 
Taxonomy of Workplace Diversity 62

regardless of their personal opinions on the matter (Furnham, 1986; Orvik, 1972). This type of response bias is often not intentional; rather, an individual may not actually be aware of the negative prejudices that he or she holds toward others. However, the outcome of both possibilities (socially desirable responses and lack of awareness of one's own prejudice) may result in respondents underreporting their negative prejudice attitudes. It would be beneficial for future research to measure workplace diversity with alternate assessment methods to help control for this limitation of self-report measures. At the same time, a self-report measure is a good place to start in gauging the perceptions of employees regarding the diversity dynamics of the organization, especially since behavior is often based on perception, even if the perception does not reflect reality (Eisenberger, Fasolo, \& Davis-LaMastro, 1990). This measure of employee perceptions can provide vital information for managers and organizational leaders that would not otherwise be available to them.

Further develop evidence of validity. Finally, more research is needed to provide further evidence of structural and discriminant validity. Further development of the Schemas and Communication dimensions would be helpful in bringing about a better model fit, as well as higher internal consistencies. Due to the relatively high correlations between the measures of discriminant validity and the WDI, both with the overall composite WDI score and certain WDI dimension scores, it would be helpful to test other measures that are theorized to not be related to workplace diversity. 
Taxonomy of Workplace Diversity 63

\section{Future Research}

Validity Studies. Future research should be conducted to examine the validity of the instrument further, since construct validity cannot be demonstrated conclusively in just one study (Hogan \& Nicholson, 1998; Landy 1986). Using the 24-item WDI in larger samples would improve information on the instrument's reliability and validity. With a large-enough sample, Item Response Theory could be used to model the response of participants for each item in the instrument (Gray-Little, Williams, \& Hancock, 1997). Because IRT provides more specific information about each item, it would enable a researcher to improve the reliability and validity of the instrument.

As mentioned above, the validity and internal consistency of the WDI could be improved by developing and testing additional items for the dimensions that had reliabilities below .70 (Schemas and Communication) and CFA factor loadings lower than .45 (Schemas) or that loaded on more than one dimension (Communication).

Examining additional constructs to establish stronger evidence of convergent and discriminant validity would be helpful. For example, I presume that a measure of employee engagement would correlate positively and significantly with the overall WDI score, but also with the Identity and Values WDI dimensions because they focus on inclusion (Identity) and how well one's sense of purpose aligns with the mission of the organization (Values), which are vital aspects of employee engagement. An additional measure of discriminant validity could include a scale of Neuroticism, since it is one of the Big Five personality factors (Barrick \& Mount, 1991), and personality traits are relatively immutable. Regarding Negative Affect, it is reasonable to assume that if a person perceives his/her workplace as unfair and exclusive, and feels excluded from vital 
Taxonomy of Workplace Diversity 64

information networks and social activities that promote career advancement, he or she would experience Negative Affect more often. Therefore, as one's perception of the diversity at work becomes more negative and WDI scores go down, scores on Negative Affect would increase at a rate that correlates significantly and negatively. However, if a person scores highly on Neuroticism, this is less likely to be affected by workplace dynamics, and more likely to stand on its own and be less correlated with the WDI composite score and dimensions.

Developments in the Taxonomy. A more parsimonious model of workplace diversity may emerge from future research using other measures of the six dimensions proposed in this study. In addition, new dimensions may surface if the data are collected during periods of organizational change or crisis. Although the present research focuses on providing an operational definition of workplace diversity, future research could specify the knowledge, skills, abilities, and other characteristics that underlie and can be used to predict more positive scores in the WDI dimensions.

Multiple Methods. In previous research, qualitative methods have been used to focus on three important aspects of diversity and to gain a more in-depth perspective of the individual, group, or institutional dynamics operating in work settings. Archival data may provide another important perspective. Observational methods can be used to target specific variables of interest. Longitudinal studies would provide evidence regarding whether WDI assessments predict later individual and organizational outcomes (e.g., health and well-being, turnover rates, profitability), directly and indirectly, related to 
Taxonomy of Workplace Diversity 65

diversity. Ultimately, future research should utilize multiple methods of assessment to provide a more complete picture and to cross validate findings (Burkard et al., 2002).

Future research should also include measures of important workplace outcomes to build a body of literature that indicates that the WDI predicts such constructs as employee engagement, organizational identity, creativity and innovation, job satisfaction, performance, turnover intentions and/or conflict.

In addition to focusing on general organizational outcomes, such as the ones mentioned above, another extension of this research could be to focus on diversity training and its outcomes, as measured, at least in part, by the WDI. Diversity training is a common method organizations use to improve workplace diversity. Goldstein and Ford (2002) describe the three main types of this training. The first focuses on raising awareness about diversity, including knowledge of the legal aspects, examination of the concept itself and how it relates to organizational effectiveness, and identification of factors that influence attitudes and behaviors toward others. The second type of diversity training focuses more directly on attitude change and increased understanding of how actions impact others. It uses role plays, videos, and interactive exercises to go beyond simple awareness to greater understanding of the negative emotional and performance effects of stereotypes, values, and behaviors on members of minority groups. The third type directly addresses the enhancement of leadership skills, such as coaching and mentoring skills, conflict management techniques, and effectively providing performance feedback. However, there are few systematic research studies that have examined the impact of diversity training, or the different types of training programs, on the subsequent behaviors of leaders (Goldstein \& Ford, 2002). Future research is needed to document 
Taxonomy of Workplace Diversity 66

whether the WDI has predictive validity for diagnosing training needs and assessing training outcomes.

\section{Implications}

The present study has potentially important implications for both theory and practice. As stated above, one theoretical implication of this study is that it provides evidence that workplace diversity is multidimensional, and the taxonomy delineates and concretely defines these dimensions. This is especially important as globalization brings about continually increasing rates of diversified workforces.

Another potential theoretical implication is the possibility that race and ethnicity may be a built-in frame of reference for diversity. That is, it may be the case that when people hear the term "diversity," they automatically think of racial, ethnic, or cultural diversity, rather than diversity on a number of other demographic categories. The initial evidence of this was found in the high correlation $(r=.70)$ between the WDI and the Workplace Prejudice and Discrimination Inventory (WPDI). The WPDI includes items that specifically refer to race or ethnicity. Example items include, "At work I feel socially isolated because of my racial/ethnic group," and "Where I work people of different racial and ethnic groups get along well with each other" (R). In contrast, my colleagues and I were intentional in developing the items and the instructions for the WDI so that neither focused either explicitly or implicitly on any one specific demographic group. This is one strength of the instrument, as described above.

However, when I further examined the possibility that ethnicity/race may be a built-in frame of reference for workplace diversity, the results were inconclusive. The correlation between the WDI and the WPDI for participants who indicated race, ethnicity 
Taxonomy of Workplace Diversity 67

or culture to be the most important aspect of their identity at work was slightly less than the participants who did not mention race, ethnicity, or culture as the most important aspect of their identity. This was contrary to what I expected if race, ethnicity or culture was a built-in frame of reference for workplace diversity.

I expected that the correlation would be higher between the WDI-24 scores and the scores on the WPDI for the participants who indicated that race, ethnicity, or culture was the most important part of their identity than for the participants who did not. However, this analysis and subsequent comparison was based on a small $(n=31)$ and unequal sample size ( $n=31$ vs. $n=171)$. In addition, the question used in the analysis was not theoretically developed to test this hypothesis. Future research should examine more carefully the possibility that race/ethnicity and/or culture form the "master" lens for diversity at work.

Since the preliminary evidence regarding race and ethnicity as a frame of reference is contradictory, other explanations for the high correlation between the WDI24 and the WPDI are possible. In line with the concept of the taxonomy, it may be that organizations with lower overall WDI scores are more likely to have prejudice and discrimination based on race/ethnicity occur. The regression analysis demonstrated that two of the six dimensions of the taxonomy, Organizational Justice and Schemas, significantly predict scores on the WPDI, which provides some evidence that the above interpretation has credence. That is, an organization in which employees perceive moral impropriety (Organizational [in]Justice) and that they are judged based on stereotypes (Schemas) is more likely to have prejudice and discrimination present. 
Taxonomy of Workplace Diversity 68

An alternative explanation would be that if prejudice and discrimination based on race and ethnicity are present in a certain workplace, prejudice and discrimination based on other demographic categories may be present as well. Thus, the overall WDI score would be lower, and the WPDI score would be commensurately higher. Both options provide a reason why WPDI scores and WDI scores would be so highly correlated, without the race, ethnicity, or culture as a frame of reference. However, contradicting the second interpretation is the presence of 12 qualitative responses stating that while the organization was doing well with diversity regarding one group (e.g., race), it was not doing as well with other groups (women, younger people).

The present research has important practical implications, as well. The WDI-24 is a promising tool for organizations to use in diagnosing and solving issues related to diversity, as well as to maximize its prospective positive outcomes. Since researchers agree that effective diversity management is the key to maximizing the potential benefits of workplace diversity, the main purpose of the taxonomy and the instrument that measures it, the WDI, is to better understand, accurately predict, and more effectively manage diversity in the workplace. The present research has the potential to aid organizational leaders in determining the particular types of selection measures, training strategies, and/or organizational development and change initiatives needed for the organization, depending on the organization's score on six specific diversity dimensions, as measured by the WDI.

The instrument provides an empirical measure of the areas in which an organization must develop in order to obtain the competitive edge that diversity has the potential to create. Specifically, the WDI provides an overall, composite score, as well as 
a score on each of the six dimensions, so organizational leaders can use empirical information in deciding how to best invest in and focus on diversity interventions. Using the instrument in this way would enable organizational leaders to see exactly which dimensions they are excelling at, and which dimensions they need to hone in on and develop. For example, an organization may receive a high score on Communication across diverse groups, but if there is a poor Diversity Climate, the organization's overall score on the WDI would not be as high as expected if one was only focusing on the fact that people in the organization communicate well across differences. This way, organizational leaders can celebrate the areas in which the organization demonstrates competency, which is important because diversity can often seem overwhelming, while at the same time, being more efficient in their use of resources toward their diversity and inclusion goals.

Because the WDI provides empirical assessment of the psychological constructs that manifest in diverse work settings, it also provides a convenient way to evaluate diversity initiatives. Organizations could use the WDI scores as baseline measures prior to the implementation of a diversity initiative, and then use it again at different intervals as the initiatives are rolled out, as a way to track and evaluate organizational progress. The WDI may also be useful as a first step in conducting a thorough needs assessment. In terms of diversity training, the present research could provide a way for organizations to set a baseline for their training program and to focus the training on the dimensions with lower baseline scores in order to determine which type of diversity training that would be most effective. For example, Communication may be linked to specific competencies, so 
Taxonomy of Workplace Diversity 70

the third type of diversity training may be best suited for this purpose, whereas Values may be improved more successfully with the second type.

As a supplement to the WDI-24, the qualitative question used in this survey would provide information for leaders to dig deeper into the specific issues that may be leading to positive or negative outcomes, such as creativity and innovation or conflict. In addition, if an organization used the demographic questionnaire this study in combination with the WDI-24, it could prove to be a useful tool for determining anonymous information on an organization's overall demographic statistics on categories that are not collected by human resources, such as sexual orientation and religion.

Providing a concrete description of the ways in which an organization is benefiting and growing from its diversity initiatives may prove effective in helping managers and employees take "bitable chunks" and in knowing that their efforts are worthwhile as they move toward becoming a truly diverse and inclusive organization one that is able to capitalize on the critical competitive edge of effectively-managed diversity. On the other hand, knowing the specific areas in which to focus future efforts is helpful in being most efficient with limited resources. Prior to this study, there was no theory-driven and psychometrically tested way to empirically measure the dynamics that arise in diverse workforces, and thus, it has been difficult to provide this vital information to organizations.

\section{Conclusion}

The attention on workplace diversity has only continued to grow. Due to rapid globalization, diversity in the workplace is becoming more complex and thus, more 
difficult to manage. There is a shortage of leaders that are able to effectively manage diversity in our increasingly diverse national context, as well as in the global context. This is in part due to the lack of clarity regarding the definition of diversity, and a precise way to measure it in organizations. This confusion has impacted the research on this topic in that diversity researchers have not been able to consistently and reliably measure, predict and provide advice on how to manage diversity in such a way as to maximize its benefits. As in most scale development studies, further research is needed to more fully develop evidence of validity. However, the Workplace Diversity Taxonomy, and the inventory that measures it, may help organizations manage diversity more effectively and develop interventions that are specific to their needs. It represents a promising step toward building diverse workplaces that are inclusive and fair, and that contribute to the well-being of all employees equally. 
Taxonomy of Workplace Diversity 72

\section{Figures and Tables}

Figure 1. Average Values of Workplace Diversity Dimensions in Preliminary Research

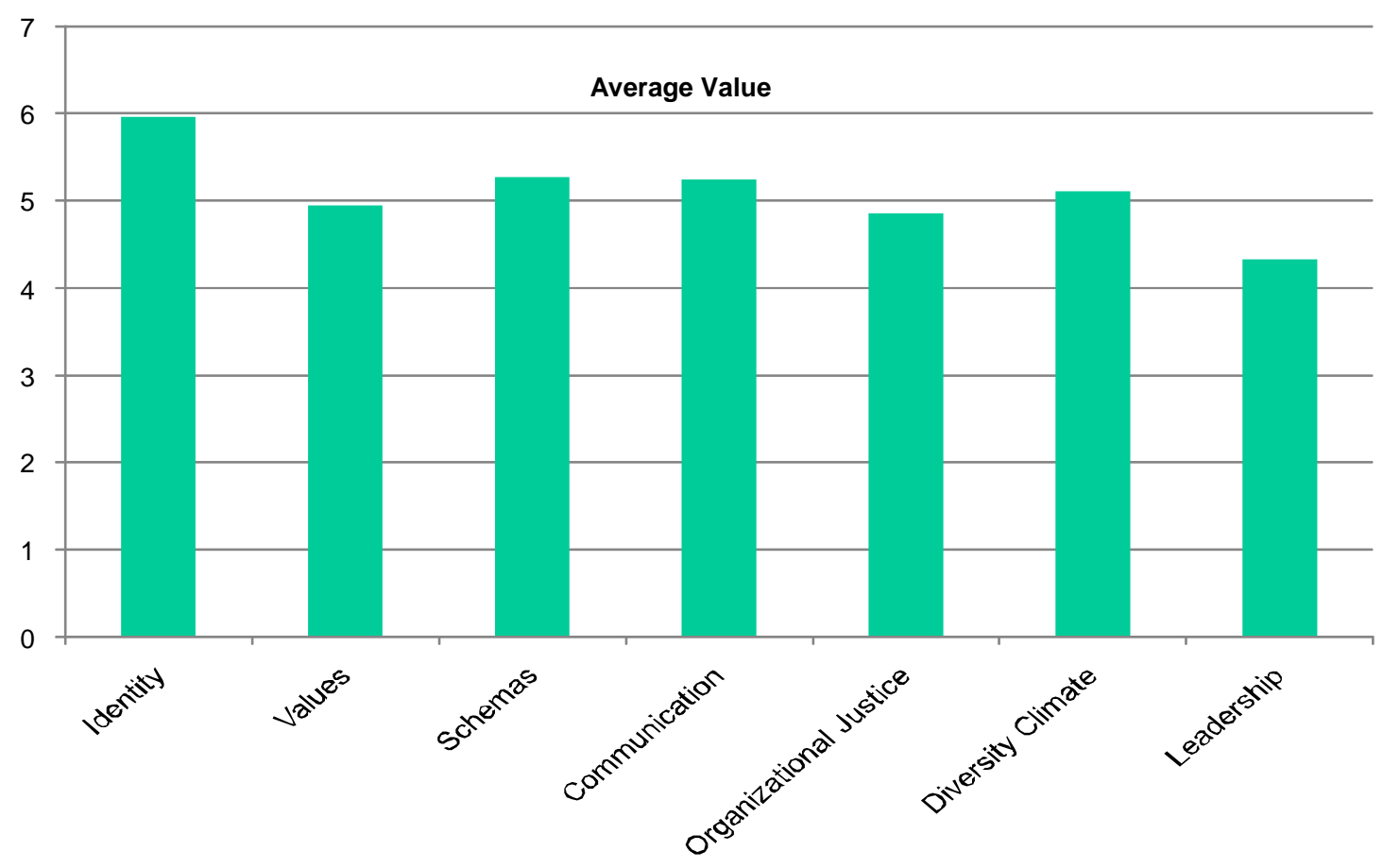


Figure 2. Workplace Diversity Taxonomy Construct Model

\begin{tabular}{lll} 
Influences on & Experienced & Diversity \\
Workplace Diversity & Diversity (WDI) & Outcomes \\
\hline
\end{tabular}

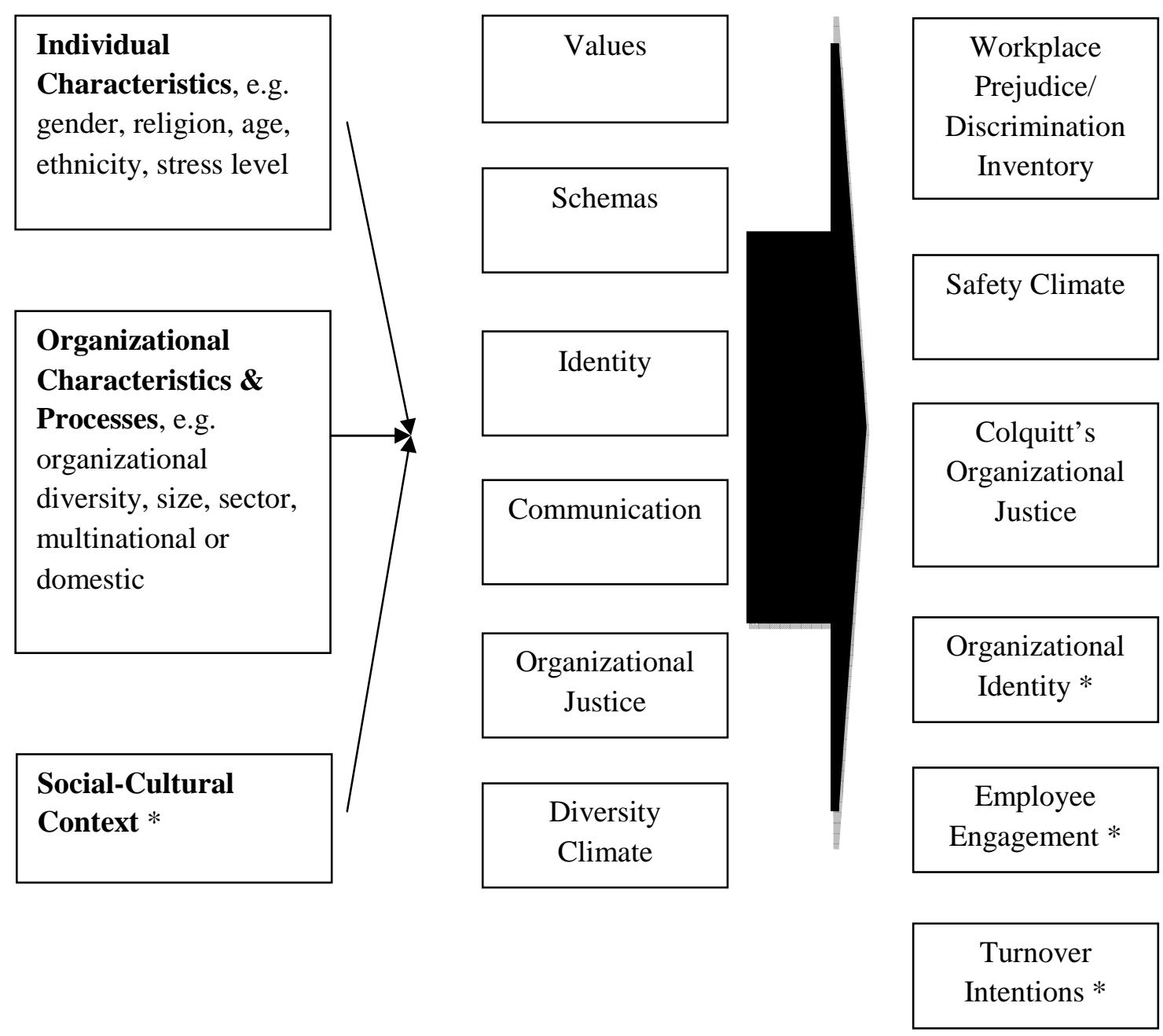

* Indicates that these constructs were not measured in the current study 
Table 1. Taxonomy of Workplace Diversity

\begin{tabular}{|c|c|}
\hline Identity & $\begin{array}{l}\text { The extent to which one perceives, feels, and behaves as if they } \\
\text { are included or excluded in a diverse work setting. }\end{array}$ \\
\hline Values & $\begin{array}{l}\text { The extent to which one's central guides influence his/her } \\
\text { perceptions of appropriate identity, preferences, beliefs and } \\
\text { behaviors in a diverse workplace. }\end{array}$ \\
\hline Schemas & $\begin{array}{l}\text { The extent to which cognitive guides lead to the organization of } \\
\text { information and the perceived patterns of behaviors, including } \\
\text { stereotypes and behavioral scripts, in diverse work settings. }\end{array}$ \\
\hline Communication & $\begin{array}{l}\text { The extent to which language barriers, differences in } \\
\text { communication styles, nonverbal communication, language } \\
\text { fluency, and cultural fluency manifest in diverse work settings. }\end{array}$ \\
\hline $\begin{array}{l}\text { Organizational } \\
\text { Justice }\end{array}$ & $\begin{array}{l}\text { The extent to which employees perceive moral propriety of the } \\
\text { distribution of resources, procedures, and interactions within a } \\
\text { diverse organization. }\end{array}$ \\
\hline $\begin{array}{l}\text { Diversity } \\
\text { Climate }\end{array}$ & $\begin{array}{l}\text { The extent to which employees share the perception that a diverse } \\
\text { organization's policies, practices, and procedures communicate a } \\
\text { strong priority given to fostering \& maintaining diversity and } \\
\text { inclusion. }\end{array}$ \\
\hline Leadership & $\begin{array}{l}\text { The extent to which the leader, or manager, in a diverse } \\
\text { organization supports diversity as a priority in the workplace. }\end{array}$ \\
\hline
\end{tabular}


Table 2. Industries Represented in Sample

\begin{tabular}{|l|c|c|}
\hline \multicolumn{1}{|c|}{ Industry } & Frequency & Percentage \\
\hline 1. Agriculture, Forestry, Fishing and Hunting & 1 & .5 \\
\hline 2. Mining & 0 & 0 \\
\hline 3. Utilities & 5 & 2.4 \\
\hline 4. Construction & 1 & .5 \\
\hline 5. Manufacturing & 9 & 4.3 \\
\hline 6. Wholesale Trade & 1 & .5 \\
\hline 7. Retail Trade & 7 & 3.4 \\
\hline 8. Transportation and Warehousing & 6 & 2.9 \\
\hline 9. Information & 3 & 1.4 \\
\hline 10. Finance and Insurance & 6 & 2.9 \\
\hline 11. Real Estate and Rental and Leasing & 2 & 1.0 \\
\hline 12. Professional, Scientific and Technical Services & 20 & 9.6 \\
\hline 13. Management of Companies and Enterprises & 2 & 1.0 \\
\hline 14. Administrative and Support and Waste and & 0 & 0 \\
\hline Remediation Services & & \\
\hline 15. Education Services & 54 & 26.0 \\
\hline 16. Health Care and Social Assistance & 38 & 18.3 \\
\hline 17. Arts, Entertainment and Recreation & 7 & 3.4 \\
\hline 18. Accommodation and Food Services & 4 & 1.9 \\
\hline 19. Other Services (except Administration) & 9 & 4.3 \\
\hline 20. Public Administration & 6 & 2.9 \\
\hline 21. Other & 27 & 13.0 \\
\hline
\end{tabular}


Taxonomy of Workplace Diversity 76

Table 3a. Item Analysis of the Communication WDI Dimension, $\alpha=.72$

\begin{tabular}{|l|c|c|}
\hline Item & $\begin{array}{l}\text { Corrected } \\
\text { Item-Total } \\
\text { Correlation }\end{array}$ & $\begin{array}{c}\text { Cronbach's Alpha } \\
\text { if Item Deleted }\end{array}$ \\
\hline $\begin{array}{l}\text { 1. I am able to express different opinions } \\
\text { without major conflict at work.* }\end{array}$ & .46 & .69 \\
\hline $\begin{array}{l}\text { 2. I strive to be sensitive to people's differences } \\
\text { when I communicate.* }\end{array}$ & .31 & .72 \\
\hline $\begin{array}{l}\text { 3. Language barriers are overcome respectfully } \\
\text { at my work.* }\end{array}$ & .35 & .70 \\
\hline $\begin{array}{l}\text { 4. I communicate effectively across identity } \\
\text { differences at work. * }\end{array}$ & .42 & .68 \\
\hline $\begin{array}{l}\text { 5. I have problems talking to co-workers who } \\
\text { are different from me. (R) * }\end{array}$ & .49 & .66 \\
\hline $\begin{array}{l}\text { 6. It is difficult to discuss tasks with my co- } \\
\text { workers because of our differences. (R) }\end{array}$ & .47 & .68 \\
\hline $\begin{array}{l}\text { 7. I feel comfortable discussing diversity } \\
\text { publicly in my organization. * }\end{array}$ & & \\
\hline
\end{tabular}

* Corrected Item-Total Correlation $<.50$ 
Taxonomy of Workplace Diversity 77

Table 3b. Item Analysis of the Diversity Climate WDI Dimension, $\alpha=.83$

\begin{tabular}{|l|c|c|}
\hline Item & $\begin{array}{l}\text { Corrected } \\
\text { Item-Total } \\
\text { Correlation }\end{array}$ & $\begin{array}{c}\text { Cronbach's Alpha } \\
\text { if Item Deleted }\end{array}$ \\
\hline $\begin{array}{l}\text { 1. My organization puts a lot of time and } \\
\text { money into diversity initiatives. }\end{array}$ & .71 & .78 \\
\hline $\begin{array}{l}\text { 2. My organization takes steps to increase } \\
\text { diversity. }\end{array}$ & .72 & .78 \\
\hline $\begin{array}{l}\text { 3. Diversity and cultural competence are } \\
\text { neglected in orientation. (R) }\end{array}$ & .60 & .80 \\
\hline $\begin{array}{l}\text { 4. My organization has anti-discrimination } \\
\text { policies.* }\end{array}$ & .34 & .79 \\
\hline $\begin{array}{l}\text { 5. My organization does not provide diversity } \\
\text { training. (R) }\end{array}$ & .63 & .78 \\
\hline $\begin{array}{l}\text { 6. Organization policies support my manager } \\
\text { in increasing diversity. }\end{array}$ & .70 & .84 \\
\hline $\begin{array}{l}\text { 7. My organization is a difficult place to work } \\
\text { if you are not in the majority. (R) * }\end{array}$ & .33 & \\
\hline
\end{tabular}

* Corrected Item-Total Correlation $<.50$ 
Table 3c. Item Analysis of the Identity WDI Dimension, $\alpha=.83$

\begin{tabular}{|l|l|l|}
\hline Item & $\begin{array}{l}\text { Corrected Item- } \\
\text { Total } \\
\text { Correlation }\end{array}$ & $\begin{array}{l}\text { Cronbach's Alpha } \\
\text { if Item Deleted }\end{array}$ \\
\hline $\begin{array}{l}\text { 1. I feel shunned by my co-workers because of } \\
\text { who I am. }(\mathrm{R}) *\end{array}$ & .45 & .82 \\
\hline 2. I feel accepted for who I am at work. & .72 & .78 \\
\hline $\begin{array}{l}\text { 3. I have to hide certain parts of who I am at } \\
\text { work. }(\mathrm{R}) *\end{array}$ & .44 & .83 \\
\hline 4. I feel separate from my co-workers. $(\mathrm{R})$ & .65 & .79 \\
\hline 5. I identify with my co-workers. & .60 & .81 \\
\hline $\begin{array}{l}\text { 6. I feel a strong sense of belonging at my } \\
\text { organization. }\end{array}$ & .60 & .79 \\
\hline 7. I consider myself part of my work team. & .66 & \\
\hline
\end{tabular}

* Corrected Item-Total Correlation $<.50$

Table 3d. Item Analysis of the Leadership WDI Dimension, $\alpha=.84$

\begin{tabular}{|l|l|l|}
\hline Item & $\begin{array}{l}\text { Corrected Item- } \\
\text { Total } \\
\text { Correlation }\end{array}$ & $\begin{array}{l}\text { Cronbach's Alpha } \\
\text { if Item Deleted }\end{array}$ \\
\hline $\begin{array}{l}\text { 1. My boss thinks diversity initiatives are a } \\
\text { waste of time. }(\mathrm{R}) *\end{array}$ & .47 & .84 \\
\hline $\begin{array}{l}\text { 2. Senior management is committed to } \\
\text { diversity in my organization. }\end{array}$ & .70 & .80 \\
\hline $\begin{array}{l}\text { 3. My manager focuses on continuous } \\
\text { learning about diversity. }\end{array}$ & .64 & .81 \\
\hline $\begin{array}{l}\text { 4. My manager is skilled at handling the } \\
\text { diversity in my workplace. }\end{array}$ & .68 & .81 \\
\hline $\begin{array}{l}\text { 5. My boss discriminates against certain } \\
\text { groups of employees regardless of their } \\
\text { performance. (R) } *\end{array}$ & .49 & .83 \\
\hline $\begin{array}{l}\text { 6. Leaders here connect diversity to the } \\
\text { organization's mission and vision. }\end{array}$ & .59 & .82 \\
\hline $\begin{array}{l}\text { 7. My manager creates a comfortable working } \\
\text { environment for all types of people. }\end{array}$ & .59 & \\
\hline
\end{tabular}

* Corrected Item-Total Correlation $<.50$ 
Taxonomy of Workplace Diversity 79

Table $3 e$. Item Analysis of the Organizational Justice WDI Dimension, $\alpha=.82$

\begin{tabular}{|l|l|l|}
\hline Item & $\begin{array}{l}\text { Corrected Item- } \\
\text { Total } \\
\text { Correlation }\end{array}$ & $\begin{array}{l}\text { Cronbach's Alpha } \\
\text { if Item Deleted }\end{array}$ \\
\hline $\begin{array}{l}\text { 1. People at work are treated fairly regardless } \\
\text { of who they are. }\end{array}$ & .70 & .78 \\
\hline $\begin{array}{l}\text { 2. Certain people are denied opportunities at } \\
\text { work because of who they are. (R) }\end{array}$ & .64 & .78 \\
\hline $\begin{array}{l}\text { 3. People can expect to be punished for } \\
\text { discriminating against a co-worker. } *\end{array}$ & .47 & .81 \\
\hline $\begin{array}{l}\text { 4. Policies that promote diversity are not } \\
\text { followed in my workplace. (R) }\end{array}$ & .55 & .78 \\
\hline $\begin{array}{l}\text { 5. Policies are implemented consistently for } \\
\text { all employees. }\end{array}$ & .67 & .81 \\
\hline $\begin{array}{l}\text { 6. I can expect to be rewarded fairly at work } \\
\text { as long as I put in a good effort. * }\end{array}$ & .47 & .81 \\
\hline $\begin{array}{l}\text { 7. Job-related information is often withheld } \\
\text { from certain groups. (R) * }\end{array}$ & .48 & \\
\hline
\end{tabular}

* Corrected Item-Total Correlation $<.50$

Table 3f. Item Analysis of the Schemas WDI Dimension, $\alpha=.62$

\begin{tabular}{|l|l|l|}
\hline Item & $\begin{array}{l}\text { Corrected Item- } \\
\text { Total } \\
\text { Correlation }\end{array}$ & $\begin{array}{l}\text { Cronbach's Alpha } \\
\text { if Item Deleted }\end{array}$ \\
\hline $\begin{array}{l}\text { 1. I am judged by the work I do rather than } \\
\text { who I am. } *\end{array}$ & .40 & .55 \\
\hline $\begin{array}{l}\text { 2. People at work base expectations of me on } \\
\text { stereotypes. (R) }\end{array}$ & .56 & .48 \\
\hline $\begin{array}{l}\text { 3. People like me are treated differently at this } \\
\text { organization. (R) } *\end{array}$ & .38 & .56 \\
\hline $\begin{array}{l}\text { 4. People lump me together with others at } \\
\text { work. (R) } * *\end{array}$ & .20 & .63 \\
\hline 5. I do not feel stereotyped at work. & .50 & .50 \\
\hline $\begin{array}{l}\text { 6. My co-workers judge me based on my } \\
\text { character. } * *\end{array}$ & .07 & .67 \\
\hline
\end{tabular}

* Corrected Item-Total Correlation $<.50$

** Corrected Item-Total Correlation $<.30$ 
Table 3g. Item Analysis of the Values WDI Dimension, $\alpha=.69$

\begin{tabular}{|l|l|l|}
\hline Item & $\begin{array}{l}\text { Corrected Item- } \\
\text { Total } \\
\text { Correlation }\end{array}$ & $\begin{array}{l}\text { Cronbach's Alpha } \\
\text { if Item Deleted }\end{array}$ \\
\hline 1. I value diversity in my workplace. & .50 & .64 \\
\hline $\begin{array}{l}\text { 2. Diversity is vital to an organization's } \\
\text { success. }\end{array}$ & .54 & .62 \\
\hline $\begin{array}{l}\text { 3. Diversity generally increases conflict at } \\
\text { work. }(\mathrm{R}) *\end{array}$ & .30 & .70 \\
\hline $\begin{array}{l}\text { 4. Our differences aid our success as a } \\
\text { company. } *\end{array}$ & .34 & .68 \\
\hline $\begin{array}{l}\text { 5. It is good to work in a place where people } \\
\text { are different from me. } *\end{array}$ & .45 & .65 \\
\hline $\begin{array}{l}\text { 6. Work teams are more efficient when people } \\
\text { are similar. }(\mathrm{R})\end{array}$ & .52 & .62 \\
\hline
\end{tabular}

* Corrected Item-Total Correlation $<.50$ 
Taxonomy of Workplace Diversity 81

Table 4. Cronbach's Alpha and Fit Statistics for Validity Measures

\begin{tabular}{|l|l|c|c|c|c|c|c|}
\hline Model & $\begin{array}{l}\text { Cronbach's } \\
\text { Alpha }\end{array}$ & $\chi^{2}$ & df & NFI & CFI & TLI & RMSEA \\
\hline $\begin{array}{l}\text { Colquitt's } \\
\begin{array}{l}\text { Organizational } \\
\text { Justice }\end{array}\end{array}$ & $\begin{array}{l}.94 \text { (Proc) } \\
.98 \text { (Distr) } \\
.96 \text { (Inter) } \\
.96 \text { (Info) }\end{array}$ & 416.78 & 164 & .93 & .95 & .94 & .09 \\
\hline $\begin{array}{c}\text { Prejudice/ } \\
\text { Discrimination }\end{array}$ & .92 & 412.24 & 90 & .77 & .81 & .74 & .31 \\
\hline $\begin{array}{c}\text { Negative } \\
\text { Affect }\end{array}$ & .89 & 372.42 & 35 & .69 & .70 & .53 & .22 \\
\hline Safety Climate & .97 & 780.88 & 104 & .78 & .80 & .74 & .18 \\
\hline
\end{tabular}

Note. $\mathrm{N}=209$. All $\chi^{2}$ values are statistically significant $(\mathrm{p}<.05)$. NFI = normed fit index; $\mathrm{CFI}=$ comparative fit index; TLI = Tucker-Lewis index; RMSEA = root mean square error of estimate.

Table 5. Initial Results of Confirmatory Factor Analyses on each Dimension (6-7 items)

\begin{tabular}{|l|c|c|c|c|c|c|c|c|}
\hline Dimension & Alpha & $\chi^{2}$ & $d f$ & $p$ & NFI & CFI & TLI & RMSEA \\
\hline $\begin{array}{l}\text { Diversity } \\
\text { Climate (7) }\end{array}$ & .83 & 51.22 & 14 & .00 & .91 & .93 & .86 & .11 \\
\hline $\begin{array}{l}\text { Organization } \\
\text { al Justice (7) }\end{array}$ & .82 & 34.02 & 14 & .00 & .92 & .95 & .90 & .08 \\
\hline Values (6) & .69 & 39.48 & 9 & .00 & .84 & .87 & .69 & .13 \\
\hline Schemas (6) & .62 & 15.62 & 9 & .07 & .91 & .95 & .89 & .06 \\
\hline $\begin{array}{l}\text { Communicati } \\
\text { on (7) }\end{array}$ & .72 & 15.25 & 14 & .36 & .93 & .99 & .99 & .02 \\
\hline Identity (7) & .83 & 39.37 & 14 & .00 & .92 & .95 & .89 & .09 \\
\hline $\begin{array}{l}\text { Leadership } \\
\text { (7) }\end{array}$ & .84 & $\begin{array}{c}124.6 \\
6\end{array}$ & 14 & .00 & .79 & .80 & .60 & .20 \\
\hline
\end{tabular}

Note. $\mathrm{N}=209$. $\mathrm{NFI}=$ normed fit index $; \mathrm{CFI}=$ comparative fit index; TLI $=$ TuckerLewis index; RMSEA = root mean square error of estimate. 
Taxonomy of Workplace Diversity 82

Table 6. Results of Confirmatory Factor Analyses on each Dimension with some Items Deleted

\begin{tabular}{|l|c|c|c|c|c|c|c|c|}
\hline Dimension & $\begin{array}{l}\text { Cron- } \\
\text { bach's } \\
\text { Alpha }\end{array}$ & $\chi^{2}$ & $d f$ & $p$ & NFI & CFI & TLI & RMSEA \\
\hline $\begin{array}{l}\text { Diversity } \\
\text { Climate } \\
\text { (5 items; \#4 \& } \\
7 \text { deleted) }\end{array}$ & .86 & 28.39 & 5 & .00 & .94 & .95 & .85 & .15 \\
\hline $\begin{array}{l}\text { Organizational } \\
\text { Justice } \\
\text { (4 items; } \\
\text { \#3,6, \& 7 } \\
\text { deleted) }\end{array}$ & .81 & 2.56 & 2 & .28 & .99 & 1.00 & .99 & .04 \\
\hline $\begin{array}{l}\text { Values } \\
\text { (5 items; \#3 } \\
\text { deleted) }\end{array}$ & .70 & 2.87 & 5 & .72 & .99 & 1.00 & 1.04 & .00 \\
\hline $\begin{array}{l}\text { Schemas (4 } \\
\text { items; } \\
\text { \#4 \& 6 } \\
\text { deleted) }\end{array}$ & .70 & 5.29 & 2 & .07 & .96 & .98 & .88 & .09 \\
\hline $\begin{array}{l}\text { Communicatio } \\
\text { n (4 items; } \\
\text { \#1,2,\& 3 } \\
\text { deleted) }\end{array}$ & .68 & .25 & 2 & .88 & 1.00 & 1.00 & 1.01 & .00 \\
\hline $\begin{array}{l}\text { Identity (5 } \\
\text { items; } \\
\text { \#1 \& 3 } \\
\text { deleted) }\end{array}$ & .83 & 4.67 & 5 & .46 & .99 & 1.00 & 1.00 & .00 \\
\hline $\begin{array}{l}\text { Leadership (7 } \\
\text { items, split into } \\
\text { two factors) }\end{array}$ & .84 & 124.66 & 14 & .00 & .79 & .80 & .60 & .20 \\
\hline $\begin{array}{l}\text { Note, N } 209 \\
\text { NFI }\end{array}$ & & & & & & & & \\
\hline
\end{tabular}

Note. $\mathrm{N}=209$. $\mathrm{NFI}=$ normed fit index $; \mathrm{CFI}=$ comparative fit index; $\mathrm{TLI}=$ TuckerLewis index; RMSEA = root mean square error of estimate. 
Taxonomy of Workplace Diversity 83

Table 7. Descriptive Statistics and Reliability Coefficients of Workplace Diversity Dimensions

\begin{tabular}{|l|c|c|c|c|}
\hline & $\begin{array}{c}\text { N of } \\
\text { Items }\end{array}$ & $\begin{array}{c}\text { Cronbach's } \\
\text { Alpha }\end{array}$ & Mean & SD \\
\hline Diversity Climate & 5 & .91 & 4.26 & 1.46 \\
\hline $\begin{array}{l}\text { Organizational } \\
\text { Justice }\end{array}$ & 4 & .82 & 5.21 & 1.27 \\
\hline Identity & 4 & .78 & 5.40 & 1.09 \\
\hline Values & 4 & .70 & 5.79 & 0.82 \\
\hline Schemas & 4 & .68 & 4.82 & 1.00 \\
\hline Communication & 3 & .67 & 5.91 & 0.91 \\
\hline \multicolumn{1}{|r|}{ Overall } & 24 & $\mathrm{n} / \mathrm{a}$ & 5.16 & 0.75 \\
\hline
\end{tabular}


Table 8. Item Loadings with Six Significant Workplace Diversity Factors, from the Principle Components Analysis

\begin{tabular}{|c|c|}
\hline Workplace Diversity Inventory (WDI) Item & $\begin{array}{l}\text { Factor } \\
\text { Loading }\end{array}$ \\
\hline \multicolumn{2}{|l|}{ Diversity Climate } \\
\hline 1. Senior management is committed to diversity in my organization. & .81 \\
\hline 2. My organization takes steps to increase diversity. & .83 \\
\hline 3. Organization policies support my manager in increasing diversity. & .81 \\
\hline $\begin{array}{l}\text { 4. My organization puts a lot of time and money into diversity } \\
\text { initiatives. }\end{array}$ & .89 \\
\hline $\begin{array}{l}\text { 5. Leaders here connect diversity to the organization's mission and } \\
\text { vision. }\end{array}$ & .86 \\
\hline \multicolumn{2}{|l|}{ Organizational Justice } \\
\hline 6. People at work are treated fairly regardless of who they are. & 69 \\
\hline 7. Policies are implemented consistently for all employees. & .69 \\
\hline $\begin{array}{l}\text { 8. My manager creates a comfortable working environment for all } \\
\text { types of people. }\end{array}$ & .72 \\
\hline $\begin{array}{l}\text { 9. Certain people are denied opportunities at work because of who } \\
\text { they are. (R) }\end{array}$ & .84 \\
\hline \multicolumn{2}{|l|}{ Identity } \\
\hline 10. I consider myself part of my work team & .41 \\
\hline 11. I feel separate from my co-workers. (R) & .55 \\
\hline 12. I identify with my co-workers. & .84 \\
\hline 13. I feel a strong sense of belonging at my organization. & $.20(.41 \mathrm{w} / 5)$ \\
\hline \multicolumn{2}{|l|}{ Values } \\
\hline 14. Diversity is vital to an organization's success. & .77 \\
\hline 15. I value diversity in my workplace. & .78 \\
\hline 16. It is good to work in a place where people are different from me. & 62 \\
\hline 17. Work teams are more efficient when people are similar. (R) & .65 \\
\hline \multicolumn{2}{|l|}{ Schemas } \\
\hline 18. People at work base expectations of me on stereotypes. (R) & .66 \\
\hline 19. I do not feel stereotyped at work. & $\begin{array}{l}.45(.55 \\
\mathrm{w} / \mathrm{ID})\end{array}$ \\
\hline 20. People lump me together with others at work. (R) & .73 \\
\hline 21. My co-workers judge me based on my character. & $.21(.89 \mathrm{w} / 5)$ \\
\hline Communication - cross loads with Values and Identity & VA ID \\
\hline $\begin{array}{l}\text { 22. It is difficult to discuss tasks with my co-workers because of our } \\
\text { differences.(R) }\end{array}$ & .34 \\
\hline $\begin{array}{l}\text { 23. I have problems talking to co-workers who are different from me. } \\
\text { (R) }\end{array}$ & .40 \\
\hline 24. I communicate effectively across identity differences at work. & .44 \\
\hline
\end{tabular}


Table 9. WDI-24 Items and Standardized Regression Weights from Confirmatory Factor Analysis

\begin{tabular}{|c|c|c|}
\hline Workplace Diversity Inventory (WDI) Item & $\begin{array}{c}\text { Standardized } \\
\text { Regression } \\
\text { Weight }\end{array}$ & $\begin{array}{l}\text { System } \\
\text { Level }\end{array}$ \\
\hline \multicolumn{3}{|l|}{ Diversity Climate } \\
\hline $\begin{array}{l}\text { 1. Senior management is committed to diversity in } \\
\text { my organization. }\end{array}$ & .90 & HM \\
\hline 2. My organization takes steps to increase diversity. & .85 & $\mathrm{O}$ \\
\hline $\begin{array}{l}\text { 3. Organization policies support my manager in } \\
\text { increasing diversity. }\end{array}$ & .83 & $\mathrm{O}$ \\
\hline $\begin{array}{l}\text { 4. My organization puts a lot of time and money into } \\
\text { diversity initiatives. }\end{array}$ & .77 & $\mathrm{O}$ \\
\hline $\begin{array}{l}\text { 5. Leaders here connect diversity to the } \\
\text { organization's mission and vision. }\end{array}$ & .76 & HM \\
\hline \multicolumn{3}{|l|}{ Organizational Justice } \\
\hline $\begin{array}{l}\text { 6. People at work are treated fairly regardless of who } \\
\text { they are. }\end{array}$ & .80 & $\begin{array}{l}\mathrm{O}, \mathrm{HM}, \mathrm{S} \text {, } \\
\text { WG, I }\end{array}$ \\
\hline $\begin{array}{l}\text { 7. Policies are implemented consistently for all } \\
\text { employees. }\end{array}$ & .74 & $\mathrm{O}, \mathrm{HM}, \mathrm{S}$ \\
\hline $\begin{array}{l}\text { 8. My manager creates a comfortable working } \\
\text { environment for all types of people. }\end{array}$ & .73 & $\mathrm{~S}$ \\
\hline $\begin{array}{l}\text { 9. Certain people are denied opportunities at work } \\
\text { because of who they are. }(\mathrm{R})\end{array}$ & 67 & $\begin{array}{l}\mathrm{O}, \mathrm{HM}, \mathrm{S} \\
\text { WG }\end{array}$ \\
\hline \multicolumn{3}{|l|}{ Identity } \\
\hline 10. I consider myself part of my work team. & .75 & WG \\
\hline 11. I feel separate from my co-workers. (R) & .70 & $\mathrm{WG}, \mathrm{O}$ \\
\hline 12. I identify with my co-workers. & .67 & WG, O \\
\hline $\begin{array}{l}\text { 13. I feel a strong sense of belonging at my } \\
\text { organization. }\end{array}$ & .66 & $\mathrm{O}$ \\
\hline \multicolumn{3}{|l|}{ Values } \\
\hline 14. Diversity is vital to an organization's success. & .72 & $\mathrm{I}$ \\
\hline 15. I value diversity in my workplace. & .65 & $\mathrm{I}$ \\
\hline $\begin{array}{l}\text { 16. It is good to work in a place where people are } \\
\text { different from me. }\end{array}$ & 63 & I \\
\hline $\begin{array}{l}\text { 17. Work teams are more efficient when people are } \\
\text { similar. (R) }\end{array}$ & .50 & I \\
\hline \multicolumn{3}{|l|}{ Schemas } \\
\hline $\begin{array}{l}\text { 18. People at work base expectations of me on } \\
\text { stereotypes. (R) }\end{array}$ & .77 & $\mathrm{HM}, \mathrm{S}, \mathrm{WG}$ \\
\hline 19. I do not feel stereotyped at work. & .66 & HM, S, WG \\
\hline $\begin{array}{l}\text { 20. People lump me together with others at work. } \\
\text { (R) }\end{array}$ & .30 & $\mathrm{HM}, \mathrm{S}, \mathrm{WG}$ \\
\hline 21. My co-workers judge me based on my character. & .09 & WG \\
\hline
\end{tabular}


Taxonomy of Workplace Diversity 86

\begin{tabular}{|l|c|c|}
\hline Communication & & \\
\hline $\begin{array}{l}\text { 22. It is difficult to discuss tasks with my co-workers } \\
\text { because of our differences.(R) }\end{array}$ & .69 & WG \\
\hline $\begin{array}{l}\text { 23. I have problems talking to co-workers who are } \\
\text { different from me. }(\mathrm{R})\end{array}$ & .66 & WG \\
\hline $\begin{array}{l}\text { 24. I communicate effectively across identity } \\
\text { differences at work. }\end{array}$ & .55 & HM, S, WG \\
\hline
\end{tabular}

Note. $\mathrm{O}=$ organization; $\mathrm{HM}=$ higher management; $\mathrm{S}=$ supervisor, $\mathrm{WG}=$ work group; $\mathrm{I}=$ individual

Table 10. Correlations between the WDI-24 Dimensions

\begin{tabular}{|l|l|l|l|l|l|l|}
\hline & 1 & 2 & 3 & 4 & 5 & 6 \\
\hline 1. Diversity Climate & 1 & & & & & \\
\hline $\begin{array}{l}\text { 2. Organizational } \\
\text { Justice }\end{array}$ & $.49^{* *}$ & 1 & & & & \\
\hline 3. Identity & $.46^{* *}$ & $.59^{* *}$ & 1 & & & \\
\hline 4. Values & .12 & .10 & $.25^{* *}$ & 1 & & \\
\hline 5. Schemas & $.22^{* *}$ & $.32^{* *}$ & $.35^{* *}$ & .10 & 1 & \\
\hline 6. Communication & $.24 * *$ & $.39 * *$ & $.49^{* *}$ & $.44^{* *}$ & $.38^{* *}$ & 1 \\
\hline
\end{tabular}

**. Correlation is significant at the .01 level.

*. Correlation is significant at the .05 level.

Table 11. Fit Statistics for Alternative Models

\begin{tabular}{|c|c|c|c|c|c|c|}
\hline Model & $\chi 2$ & $d f$ & NFI & CFI & TLI & RMSEA \\
\hline Univariate & 1006.71 & 252 & .54 & .60 & .52 & .12 \\
\hline $\begin{array}{c}\text { Two- } \\
\text { Factor }\end{array}$ & 767.90 & 251 & .65 & .73 & .67 & .10 \\
\hline $\begin{array}{c}\text { Five- } \\
\text { Factor }\end{array}$ & 429.21 & 242 & .80 & .90 & .88 & .06 \\
\hline $\begin{array}{c}\text { Six- } \\
\text { Factor }\end{array}$ & 346.01 & 237 & .84 & .94 & .93 & .05 \\
\hline
\end{tabular}

Note. $\mathrm{N}=209$. All $\chi^{2}$ values are statistically significant $(\mathrm{p}<.05)$. NFI $=$ normed fit index CFI = comparative fit index; TLI = Tucker-Lewis index; RMSEA = root mean square error of estimate. 
Taxonomy of Workplace Diversity 87

Table 12. Correlation of the WDI-24 Dimensions and Validity Scales

\begin{tabular}{|l|c|c|c|c|}
\hline & $\begin{array}{c}\text { Colquitt's Org } \\
\text { Justice }\end{array}$ & WPDI & Safety Climate & $\begin{array}{c}\text { Negative } \\
\text { Affect }\end{array}$ \\
\hline $\begin{array}{l}\text { Diversity } \\
\text { Climate }\end{array}$ & $.34^{* *}$ & $-.43^{* *}$ & $.47^{* *}$ & $-.29^{* *}$ \\
\hline $\begin{array}{l}\text { WDI } \\
\begin{array}{l}\text { Organizational } \\
\text { Justice }\end{array}\end{array}$ & $.63^{* *}$ & $-.72^{* *}$ & $.45^{* *}$ & $-.31^{* *}$ \\
\hline Identity & $.53^{* *}$ & $-.50^{* *}$ & $.51^{* *}$ & \\
\hline Schemas & $.31^{* *}$ & $-.43^{* *}$ & $.15^{*}$ & $-.31^{* *}$ \\
\hline Values & $.16^{*}$ & $-.18^{* *}$ & .06 & $-.22^{* *}$ \\
\hline Communication & $.36^{* *}$ & $-.50^{* *}$ & $.23^{* *}$ & $-.29^{* *}$ \\
\hline
\end{tabular}

$*$. Correlation is significant at the .05 level.

**. Correlation is significant at the .01 level.

Table 13. Correlations of Overall WDI-24 and Validity Scales

\begin{tabular}{|c|c|c|c|c|c|}
\hline & 1 & 2 & 3 & 4 & 5 \\
\hline $\begin{array}{l}1 . \\
\text { Composite } \\
\text { WDI-24 }\end{array}$ & 1 & & & & \\
\hline $\begin{array}{l}\text { 2. Colquitt } \\
\text { Org } \\
\text { Justice }\end{array}$ & $.59 * *$ & 1 & & & \\
\hline 3. WPDI & $-.70 * *$ & $-.46 * *$ & 1 & & \\
\hline $\begin{array}{l}\text { 4. Safety } \\
\text { Climate }\end{array}$ & $.52 * *$ & $.41 * *$ & $.34 * *$ & 1 & \\
\hline $\begin{array}{l}5 . \\
\text { Negative } \\
\text { Affect }\end{array}$ & $-.39 * *$ & -.31 & $.27 * *$ & $-.23 * *$ & 1 \\
\hline
\end{tabular}

**. Correlation is significant at the .01 level.

Table 14. Descriptive Statistics by Demographic Category

\begin{tabular}{|l|l|l|}
\hline & Mean & $\begin{array}{l}\text { Standard } \\
\text { Deviation }\end{array}$ \\
\hline White/European American & 5.15 & 0.73 \\
\hline Asian-American/Pacific Islander & 5.34 & 0.84 \\
\hline African-American/Black & 4.89 & 0.87 \\
\hline Latino/Hispanic & 5.11 & 0.77 \\
\hline Heterosexual/Straight & 5.17 & 0.76 \\
\hline Lesbian, Gay, Bisexual, Transgender, Queer & 5.14 & 0.63 \\
\hline
\end{tabular}


Taxonomy of Workplace Diversity 88

\section{References}

Acquavita, S. P., Pittman, J., Gibbons, M., \& Castellanos-Brown, K. (2009). Personal and organizational diversity factors' impact on social workers' job satisfaction: Results from a national internet-based survey. Administration in Social Work, 33(2), 151-166.

Adler, N. J. \& Gunderson, A. (2008). International dimensions of organizational behavior, fifth edition. Mason, OH: South-Western Cengage Learning.

Alliger, G. M., Tannenbaum, S. I., Bennett, JR., W., Traver, H., \& Shotland, A. (1997). A meta-analysis of the relations among training criteria. Personnel Psychology, 50, 341-358.

Avery, D. R., McKay, P. F., and Wilson, D. C. (2007). Engaging the aging workforce: The relationship between perceived age similarity, satisfaction with coworkers, and employee engagement, Journal of Applied Psychology, 92, 6, 1542-1556.

Barrick, M. R., \& Mount, M. K. (1991). The big five personality dimensions and job performance: A meta-analysis. Personnel Psychology, 44, pp. 1-25.

Bar-Tal, D. (1997). Formation and change of ethnic and national stereotypes: An integrative model. International Journal of Intercultural Relations, 21(4), 491523.

Bar-Tal, D., \& Labin, D. (2001). The effect of a major event on stereotyping: Terrorist attacks in Israel and Israeli adolescents' perceptions of Palestinians, Jordanians and Arabs. European Journal of Social Psychology, 31, 1-17.

Bassett-Jones, Nigel (2005). The paradox of diversity management, creativity and innovation. Creativity and Innovation Management (0963-1690), 14 (2), p. 169. 
Taxonomy of Workplace Diversity 89

Bauer, T.N., \& Erdogan, B. (2009). Organizational Behavior. Nyack, NY: Flat World Knowledge.

Bentler, P. M. (1990). Comparative fit indices in structural equation modeling. Psychological Bulletin, 107, 238-246.

Bentler, P. M., \& Bonett, D. G. (1980). Significance tests and goodness of fit in the analysis of covariance structures. Psychological Bulletin, 88, 588-606.

Black, J. S. (1990). Locus of control, social support, stress, and adjustment in international transfers. Asia-Pacific Journal of Management, 7, 1-29.

Blair, I. V. (2002). The malleability of automatic stereotypes and prejudice. Personality and Social Psychology Review, 6(3), 242-261.

Bradfield, M.O. (2000). The Influence of Offense-generated Factors, Social Perceptions, and Preexisting Individual Characteristics on Restorative Justice Coping Responses. Unpublished Doctoral Dissertation, Georgia State University, Atlanta, Georgia.

Brewer, M. (1991). The social self: On being the same and different at the same time. Personality and Social Psychology Bulletin, 17, 475-482.

Brown, M. W., \& Cudeck, R. (1993). Single sample cross-validation indices for covariance structures. Multivariate Behavioral Research, 24, 445-455.

Bureau of Labor Statistics (2011), Table A-6. Employment status of the civilian population by sex, age, and disability status, not seasonally adjusted. Accessed on May 11, 2011 http://www.bls.gov/news.release/empsit.t06.htm 
Burkard, A. W., Boticki, M. A., \& Madson, M. B. (2002). Workplace discrimination, prejudice, and diversity measurement: A review of instrumentation. Journal of Career Assessment, 10, 343.

Butterfield, L. D., Borgen, W. A., Amundson, N. E., \& Maglio, A.T. (2005). Fifty years of the critical incident technique: 1954-2004 and beyond. Qualitative Research, 5, 475.

Byrne, B. M. (2001). Structural equation modeling with Amos: Basic concepts, applications, and programming. Mahwah, NJ: Lawrence Erlbaum.

Caldwell, Q. S., Mack, D., Johnson, C. D., \& Biderman, M. D. (2002). Value for diversity as a moderator of organizational relationships. Poster presented at the $17^{\text {th }}$ Annual Meeting of the Society for Industrial and Organizational Psychology, Toronto, Canada.

Chell, E. (1998). Critical Incident Technique, in G. Symon and C. Cassell (Eds.) Qualitative Methods and Analysis in Organizational Research: A Practical Guide, pp. 51-72. London: Sage.

Cho, S., \& Mor Barak, M. E. (2008). Understanding diversity and inclusion in a perceived homogenous culture: A study of organizational commitment and job performance among Korean employees. Administration in Social Work, 32(4), $100-126$.

Chrobot-Mason, D. \& Ruderman, M. N. (2004). Leadership in a diverse workplace. In M. S. Stockdale and F. J. Crosby (Eds.), The Psychology and Management of Workplace Diversity (pp. 100-121). Malden, MA: Blackwell. 
Taxonomy of Workplace Diversity 91

Chung, Y. B., \& Harmon, L. W. (1999). Assessment of perceived occupational opportunity for Black Americans. Journal of Career Assessment, 7, 45-62.

Colquitt, J. A. (2001). On the dimensionality of organizational justice: A construct validation of a measure. Journal of Applied Psychology, 86, 3, 386-400.

Combs, G. M. (2003). The duality of race and gender for managerial African American women: Implications of informal social networks on career advancement. Human Resource Development Review, 2(4), 385-405.

Cox, T. (1991). The multicultural organization. Academy of Management Executive, 5, 34-47.

Cox, T. (1994). Cultural diversity in organizations: Theory, research and practice. San Francisco, CA: Berrett-Koehler.

Cox, T. (2001). Creating the multicultural organization: A strategy for capturing the power of diversity. San Francisco: Jossey-Bass.

Cox, T. (2004). Problems with research by organizational scholars on issues of race and ethnicity. Journal of Applied Behavioral Science, 40, 124-145.

Cox, T. and Blake, H. (1991). Managing cultural diversity: Implications for organizational competitiveness. Academy of Management Executive, 5(3), 45-57.

Creswell, J.W. (1998). Qualitative Inquiry and Research Design: Choosing Among the Five Traditions. Thousand Oaks, CA: Sage.

Cronbach, L. J., \& Meehl, P. H. (1955). Construct validity in psychological tests. Psychological Bulletin, 52, 281-302. 
Taxonomy of Workplace Diversity 92

Cropanzano, R., Li, A., \& James, K. (2007). Intraunit justice and interunit justice and the people who experience them. In F. Dansereau \& F. J. Yammarino (Eds.). Research in Multilevel Issues (Vol. 6, pp. 415-438). Englewood Cliffs, NJ: Erlbaum.

Crosby, F., Bromley, S., \& Saxe, L. (1980). Recent unobtrusive studies of Black-andWhite discrimination and prejudice: A literature review. Psychological Bulletin, $87,546-563$.

D’Almeida, C. M. (2007). The effects of cultural diversity in the workplace. Unpublished dissertation, Capella University, Ann Arbor, Retrieved August, 22, 2008, from Dissertations and Theses database.

Dass, P., \& Parker, B. (1999). Strategies for managing human resource diversity: From resistance to learning. Academy of Management Executive, 13, 68-80.

Dahm, M. J., Willems, E. P., Ivancevich, J. M. and Graves, D. E., (2009). Development of an organizational diversity needs analysis instrument. Journal of Applied Social Psychology, 39, 2, 283-318.

Devine, P. G. (1989). Stereotypes and prejudice: Their automatic and controlled components. Journal of Personality and Social Psychology, 56, 5-18.

Dunning, D., \& Sherman, D. A. (1997). Stereotypes and tacit inference. Journal of Personality and Social Psychology, 73, 459-471.

Dunton, B. C., \& Fazio, R. H. (1997). An individual difference measure of motivation to control prejudiced reactions. Personality and Social Psychology Bulletin, 23, 316326. 
Taxonomy of Workplace Diversity 93

Dworkin, F., Dworkin, D., \& Chafetz, I. (1986). The effects of tokenism on work alienation among urban public school teachers. Work \& Occupations, 13, 399420.

Eisenberger, R., Fasolo, P., \& Davis-LaMastro, V. (1990). Perceived organizational support and employee diligence, commitment, and innovation. Journal of Applied Psychology, 75(1), 51-59.

Enteman, W. (1996), Stereotyping, prejudice, and discrimination. In P. M. Lester (Ed.), Images that injure: Pictorial stereotypes in the media (pp.9-14). Westport, CT: Praeger.

Ely, R. J., \& Thomas, D. A. (2001). Cultural diversity at work: The effects of diversity perspectives on work group processes and outcomes. Administrative Science Quarterly, 46, 229-273.

Federal Glass Ceiling Commission (FGCC) (1995), Good for Business: Making Full Use of the Nation's Human Capital. The Environmental Scan, A Fact-Finding Report of the Federal Glass Ceiling Commission, Government Printing Office, Washington, DC.

Findler, L., Wind, L., \& Mor Barak, M. E. (2007). The challenge of workforce management in a global society: Modeling the relationship between diversity, organizational culture, and employee well-being, job satisfaction and organizational commitment. Administration in Social Work, 31(3), 63-94.

Flanagan, J.C. (1954). The Critical Incident Technique. Psychological Bulletin 51(4): 327-58. 
Fleiss, J. L. (1981). Statistical methods for rates and proportions. New York: Wiley.

Foldes H. J., Duehr, E. E., \& Ones, D. S. (2008). Group differences in personality: Metaanalyses comparing five U.S. racial groups. Personnel Psychology, 61, 579-616.

Furnham, S. (1986). Response bias, social desirability and dissimulation. Personality and Individual Differences, 7, 385-400.

Gaertner, S. L., \& Dovidio, J. F. (1986). The aversive form of racism. In S. L. Gaertner \& J. F. Dovidio (Eds.), Prejudice, discrimination, and racism (pp. 61-89). New York: Academic Press.

Gelfand, M. J., Nishii, L. H., Raver, J., \& Schneider, B. (2005). Discrimination in organizations: An organizational level systems perspective. In R. Dipboye \& A. Colella (Eds.), Discrimination at work: The psychological and organizational bases (pp. 89-116). Mahwah, NJ: Erlbaum.

Glazier, J. A. (2003). Developing cultural fluency: Arab and Jewish students engaging in one another's company. Harvard Educational Review, 73(2), 141-163.

Goldstein, I. L. \& Ford, J. K., (2002). Training in Organizations. Fourth Edition. Belmont, CA: Wadsworth Group.

Gray, M., Kurihara, T., Hommen, L., \& Feldman, J. (2007). Networks of exclusion: job segmentation and social networks in the knowledge economy. Equal Opportunities International, 26(2), 144-161.

Gray-Little, B., Williams, V. S. L., \& Hancock, T. D. (1997). An item response theory analysis of the Rosenberg self-esteem scale. Personality and Social Psychology Bulletin, 23 (5), 443-451. 
Greenwald, A. G., \& Banaji, M. R. (1995). Implicit social cognition: Attitudes, selfesteem, and stereotypes. Psychological Review, 102, 4-27.

Guzzo, R., \& Dickson, M. (1996). Teams in organizations: Recent research on performance and effectiveness. Annual Review of Psychology, 47, 307-338.

Harvey, C.P., \& Allard, M.J. (2005). Understanding and managing diversity: Readings, cases and exercises. New Jersey: Pearson Education.

Haq, R. (2004). International perspectives on workplace diversity. In M. S. Stockdale and F. J. Crosby (Eds.), The psychology and management of workplace diversity (pp. 277-298). Malden, MA: Blackwell.

Hays-Thomas, R. (2004). Why now? The contemporary focus on managing diversity. In M. S. Stockdale and F. J. Crosby (Eds.), The psychology and management of workplace diversity (pp. 3-30). Malden, MA: Blackwell.

Hegarty, W. H., \& Dalton, D. R. (1995). Development and psychometric properties of the organizational diversity inventory (ODI). Educational and Psychological Measurement, 55, 1047-1052.

Highhouse, S., Stierwalt, S. L., Bachiochi, P., Elder, A. E., \& Fisher, G. (1999). Effects of advertised human resource management practices on attraction of African American applicants. Personnel Psychology, 52,424-442.

Hinkin, T. R. (1998). A brief tutorial on the development of measures for use in survey questionnaires. Organizational Research Methods, 1, 104-121.

Hogan, R., \& Nicholson, R. A. (1988). The meaning of personality test scores. American Psychologist, 43, 621-626. 
Taxonomy of Workplace Diversity 96

Hogg, M. A. \& Terry, D. J. (2000). Social identity and self-categorization processes in organizational contexts. Academy of Management Review, 25, 121-140.

House, R. J., Hanges, P. J., Javidan, M., Dorfman, P.W. \& Gupta, V. (Eds., 2004). Culture, leadership and organizations: The GLOBE study of 62 societies.

Ibarra, H. (1995). Race, opportunity, and diversity of social circles in managerial networks. Academy of Management Journal, 38, 673-703.

James, K., Lovato, C., \& Cropanzano, R. (1994). Correlational and known-group comparison validation of a workplace prejudice/discrimination inventory. Journal of Applied Social Psychology, 24, 1573-1592.

John, O. P. \& Benet-Martinez, V (2000). Measurement: Reliability, construct validation, and scale construction. (Eds.) Reis, H \& Judd, C. M. Handbook of Research Methods in Social and Personality Psychology. Cambridge, UK: Cambridge University Press, 339-369.

Judge, T.A., \& Colquitt, J.A. (2004). Organizational justice and stress: The mediating role of work-family conflict. Journal of Applied Psychology, 89, 395-404.

Judy, R. W., \& D’Amico, C. (1997). Workforce 2020: Work and workers in the 21st century. Indianapolis, IN: Hudson Institute.

Kim, S. S., \& Gelfand, M. J. (2003). The influence of ethnic identity on perceptions of organizational recruitment. Journal of Vocational Behavior, 63, 396-416.

King, E. B., \& Cortina, J. M. (in press). Stated and unstated barriers and opportunities to creating LGBT-supportive organizations. Industrial-Organizational Psychology: Perspectives of Science and Practice. 
Taxonomy of Workplace Diversity 97

King, E. B., \& Cortina, J. M. (in press). The social and economic imperative of LGBTsupportive organizations. Industrial-Organizational Psychology: Perspectives of Science and Practice.

Kirkpatrick, D. L. (1959). Techniques for evaluating training programs. Journal of the American Society of Training and Development, 13, 3-9.

Koper, G., Knippenberg, D., Bouhuijs, F., Vermunt, R., \& Wilke, H. (1993). Procedural fairness and self esteem. European Journal of Social Psychology, 23, 313-325.

Kossek, E. E., and Zonia, S. C. (1993). Assessing diversity climate: A field study of reactions to employer efforts to promote diversity. Journal of Organizational Behavior, 14, 1, 61-81.

Kossek, E. E., Markel, K. S., \& McHugh, P. P. (2003). Increasing diversity as an HRM change strategy. Journal of Organizational Change Management, 16, 328-352.

Kraiger, K., Ford, J. K., \& Salas, E. (1993). Application of cognitive, skill-based, and affective theories of learning outcomes to new methods of training evaluation.

Landy, F. J. (1986). Stamp Collecting versus science: Validation as hypothesis testing. American Psychologist, 41, 1183-1192.

Larkey, L. K. (1996). The development and validation of the Workforce Diversity Questionnaire: An instrument to assess interactions in diverse workgroups. Management Communication Quarterly, 9, 296-337.

Lau, D. C., \& Murnighan, J. K. (1998). Demographic diversity and faultlines: The compositional dynamics of organizational groups. Academy of Management Review, 23: 325-340. 
Lubensky, M. E., Holland, S. L., Wiethoff, C., and Crosby, F. J. (2004). Diversity and sexual orientation: Including and valuing sexual minorities in the workplace. In M. S. Stockdale and F. J. Crosby (Eds.), The psychology and management of workplace diversity (pp. 206-223). Malden, MA: Blackwell.

Markus, H. R., \& Kitayama, S. (1991). Culture and the self: Implications for cognition, emotion, and motivation. Psychological Review, 98, 224-253.

McConahay, J. B. (1986). Modern racism, ambivalence, and the modern racism scale. In J. F. Dovidio \& S. L. Gaertner (Eds.), Prejudice, discrimination, and racism (pp. 91-125). Orlando, FL: Academic Press.

McDonald, S., Lin, N., \& Ao, D. (2009). Networks of opportunity: Gender, race and job leads. Social Problems, 56(3), 385-402.

McKay, P. F., \& Avery, D. R. (2006). What has race got to do with it? Unraveling the role of racioethnicity in job seekers' reactions to site visits. Personnel Psychology, 59, 395-429.

McKay, P. F., Avery, D. R., Tonidandel, S., Morris, M. A., Hernandez, M., \& Hebl, M. R. (2007). Racial differences in employee retention: Are diversity climate perceptions the key? Personnel Psychology, 60, 35-62.

Messick, D. M. \& Mackie, D. M. (1989). Intergroup relations. Annual Review of Psychology, 40, 51-81.

Milliken, F., \& Martins, L. (1996). Searching for common threads: Understanding the multiple effects of diversity in organizational groups. Academy of Management Review, 21, 402-433. 
Taxonomy of Workplace Diversity 99

Miville, M. L., Gelso, C. J., Pannu, R., Liu, W., Touradji, P., Holloway, P., \& Fuertes, J. (1999). Appreciating similarities and valuing differences: The Miville-Guzman Universality-Diversity Scale. Journal of Counseling Psychology, 46, 291-307.

Molinsky, A. L. (2005). Language fluency and the evaluation of cultural faux pa: Russians interviewing for jobs in the United States. Social Psychology Quarterly, 68(2), 103-120.

Montei, M. S., Adams, G. A., \& Eggers, L. M. (1996). Validity of scores on the attitudes toward diversity scale (ATDS). Educational and Psychological Measurement, 56, 293-303.

Mor Barak, M. E., Cherin, D. A., \& Berkman, S. (1998). Organizational and personal dimensions in diversity climate. Journal of Applied Behavioral Science, 34, 82104.

Mor Barak, M. E. (2011). Managing Diversity: Toward a Globally Inclusive Workplace. (2nd ed.) Thousand Oaks, CA: Sage Publishing.

Mor Barak, M. E., Findler, L., \& Wind, L. (2003). Cross-cultural aspects of diversity and well-being in the workplace: An international perspective. Journal of Social Work Research and Evaluation, 4(2), 49-73.

Mor Barak, M. E., \& Levin, A. (2002). Outside the corporate mainstream and excluded from the work community: A study of diversity, job satisfaction and well-being. Community, Work \& Family, 5(2), 133-157.

Neal, R. A., Griffin, M. A. \& Hart, P. M. (2000). The impact of organizational climate on safety climate and individual behavior. Safety Science, 34, 99-109. 
Neal, A., \& Griffin, M. A. (2006). A Study of the Lagged Relationships Among Safety Climate, Safety Motivation, Safety Behavior, and Accidents at the Individual and Group Levels. Journal of Applied Psychology, 91(4), 946-953.

Nelson, E. S. and Krieger, S. L. (1997). Changes in attitude toward homosexuality in college students: Implementation of a gay men and lesbian peer panel. Journal of Homosexuality, 33, 63-81.

Noe, R. A., \& Ford, J. K. (1992). Emerging issues and new directions for training research. In G.Ferris \& K. Rowland (Eds.), Research in personnel and human resource management (pp. 345-384). Greenwich, CT: JAI.

Nunnally, J. C., \& Bernstein, I. H. (1994). Psychometric theory (Third ed.). New York: McGraw-Hill.

Offermann, L. R. and Phan, L. U. (2002). Culturally intelligent leadership for a diverse world. In R.E. Riggio, S. E. Murphy, and F. J. Pirozzolo (eds.), Multiple intelligences and leadership (pp. 187-214). Mahwah, NJ: Lawrence Erlbaum Associates.

Orvik, J. M. (1972). Social desirability for the individual, his group and society. Multivariate Behavioral Research, 7, 3-32.

Pekerti, A. A., \& Thomas, D. C. (2003). Communication in intercultural interaction: An empirical investigation of indicentric and sociocentric communication styles. Journal of Cross-Cultural Psychology, 34(2), 139-154.

Pettigrew, T. F., \& Martin, J. (1987). Shaping the organizational context for black American inclusion. Journal of Social Issues, 43, 41-78. 
Taxonomy of Workplace Diversity 101

Ponterotto, J. G., \& Casas, J. M. (1991). Handbook of racial/ethnic minority counseling research. Springfield, IL: Charles C Thomas.

Pugh, S. D., Dietz, J., Brief, A. P., \& Wiley, J. W. (2008). Looking inside and out: The impact of employee and community demographic composition on organizational diversity climate. Journal of Applied Psychology, 93, 6, 1422-1428.

Pulakos, E. D., Arad, S., Donovan, M. A., \& Plamondon, K. E. (2000). Adaptability in the workplace: Development of a taxonomy of adaptive performance. Journal of Applied Psychology, 85, 4, 612-624.

Ragins, B. R. (2004) Sexual orientation in the workplace: The unique work and career experiences of gay, lesbian and bisexual workers. Research in Personnel and Human Resources Management, 23, 37-122.

Roberson, Q. R., \& Colquitt, J. A. (2005). Shared and configural justice: A social network model of justice in teams. Academy of Management Review, 30, 3, 595607.

Rotter, J. (1966). Generalized expectancies for internal versus external control of reinforcements, Psychological Monographs, 80, Whole No. 609.

Rotundo, M., Nguyen, D. H., \& Sackett, P. R. (2001). A Meta-Analytic review of gender differences in perceptions of sexual harassment. Journal of Applied Psychology, $86,914-922$.

Rupp, D. E., Bashshur, M. \& Liao, H. (2007). Justice climate past, present, and future: models of structure and emergence. In F. Dansereau, \& F. J. Yammarino (Eds.), Research In Multilevel Issues (Vol. 6). Englewood Cliffs, NJ: Erlbaum. 
Taxonomy of Workplace Diversity 102

Rynes, S. \& Rosen, B. (1995). A field survey of factors affecting the adoption and perceived success of diversity training. Personnel Psychology, 48, 247-270.

Schaller, M. (1991). Social categorization and the formation of social stereotypes. Further evidence for biased information processing in the perception of groupbehavior correlations. European Journal of Social Psychology, 21, 25-35.

Scott, J. C. (1999, January/February). Developing cultural fluency: The goal of international business communication instruction in the $21^{\text {st }}$ century. Journal of Education for Business, 140-143.

Slaughter, M. (2010, March). How U.S. Multinational Companies Strengthen the U.S. Economy: Data Update. Business Roundtable. Accessed on May 3, 2011. http://www.uscib.org/docs/foundation_multinationals_update.pdf

Sniderman, P., \& Tetlock, P. (1986). Symbolic racism: Problems of motive attribution in political analysis. Journal of Social Issues, 42, 423-447.

Spector, P. E. (1988). Development of the work locus of control scale. Journal of Occupational Psychology, 61 (4), 335-340.

Stano, M. (1983) The critical incident technique: A description of the method. Annual Meeting of the Southern Speech Communication Association, April, Lincoln, Nebraska.

Stockdale, M. S. \& Cao, C. (2004). Looking back and heading forward: Major themes of the psychology and management of workplace diversity. In M. S. Stockdale and F. J. Crosby (eds.), The psychology and management of workplace diversity (pp. 300-316). Malden, MA: Blackwell. 
Taxonomy of Workplace Diversity 103

Stricker, L. J. (1963). Acquiescence and social desirability response styles, item characteristics, and conformity. Psychological Reports, 12, 319 - 341.

Tajfel, H., \& Turner, J. C. (1979). An integrative theory of intergroup conflict. In W. G. Austin \& S. Worchel (Eds.), The social psychology of intergroup relations (pp. 33-47). Pacific Grove, CA: Brooks/Cole.

Tavris, C., \& Aronson, E. (2007). Mistakes were made (but not by me): Why we justify foolish beliefs, bad decisions, and hurtful acts. Orlando, FL: Harcourt.

Taylor, A. \& James, K. (August, 2010). Toward the well-being of all: Integrating diversity dynamics and organizational justice dimensions. Presentation at the Academy of Management Meeting, Montreal, Canada.

Taylor, D. M., \& Moghaddam, F. M. (1994). Theories of intergroup relations: International social psychological perspectives (2nd ed.). New York: Praeger.

Thomas, K. (2005). Diversity dynamics in the workplace. Belmont, CA: Thomson Wadsworth.

Tomaskovic-Devey, D., Zimmer, C., Stainback, K., Robinson, C., Taylor, T., \& McTague, T. (2006). Documenting desegregation: Segregation in American workplaces by race, ethnicity, and sex, 1966-2003. American Sociological Review, 71, 565-588.

Triandis, H. C. (2003). The Future of Workforce Diversity in International Organisations: A Commentary. Applied Psychology: An International Review, 52, $486-495$.

Tucker, L. R., \& Lewis, C. (1973). A reliability coefficient for maximum likelihood factor analysis. Psychometrika, 38, 1-10. 
Taxonomy of Workplace Diversity 104

Turner, J. C. (1981). The experimental social psychology of inter-group behavior. In J. C. Turner \& H. Giles (Eds.), Intergroup behavior (pp. 66-101). Chicago, IL: University of Chicago Press.

U.S. Department of Health and Human Services, Office on Disability, Prevalence and Impact, Fact Sheet, accessed on May 3, 2011. http://www.hhs.gov/od/about/fact_sheets/prevalenceandimpact.html

Weiland, A. J. (2004). Business leadership and diversity: The relationships between team diversity climate, leaders' diversity attitudes, and leadership styles. Unpublished dissertation, University of Iowa: Iowa City, Retrieved August, 22, 2008, from Dissertations and Theses database.

Watson, D., Clark, L. A., \& Tellegen, A. (1988). Development and validation of brief measures of positive and negative affect: The PANAS scales. Journal of Personality and Social Psychology, 54, 1063-1070.

Watson, D., \& Clark, L. A. (1999). The PANAS-X: Manual for the Positive and Negative Affect Schedule - Expanded Form. Psychology Publications, University of Iowa. Woolsey, L.K. (1986). The critical incident technique: An innovative qualitative method of research. Canadian Journal of Counseling 20, 4, 242-54.

Zerbe, W. J., \& Paulhus, D. L (1987). Socially desirable responding in organizational behavior: A re-conception. Academy of Management Review, 12, 250-264.

Zohar, D., \& Luria, G. (2005). A Multilevel Model of Safety Climate: Cross-Level Relationships Between Organization and Group-Level Climates. Journal of Applied Psychology, 90(4), 616-628. 


\section{Appendices}

Appendix A. Workplace Diversity Inventory-24

\section{Instructions:}

Listed below are a number of statements that could be used to describe a variety of factors relating to diversity within your workplace. Please take some time to reflect on your own social identity (for example, your age, socioeconomic status, gender, sexual orientation, ethnicity, etc.).

Now consider your interactions with your co-workers based on your identity. Please read each statement carefully and indicate the extent to which you agree by choosing the appropriate number on the scale provided.

If you work at more than one organization, please choose one and answer with only that organization in mind. Your opinion is of interest; there is no right or wrong answer.

\section{Diversity Climate}

1. Senior management is committed to diversity in my organization.

2. My organization takes steps to increase diversity.

3. Organization policies support my manager in increasing diversity.

4. My organization puts a lot of time and money into diversity initiatives.

5. Leaders here connect diversity to the organization's mission and vision.

\section{Organizational Justice}

6. People at work are treated fairly regardless of who they are.

7. Policies are implemented consistently for all employees.

8. My manager creates a comfortable working environment for all types of people.

9. Certain people are denied opportunities at work because of who they are. (R)

\section{Identity}

10. I consider myself part of my work team

11. I feel separate from my co-workers. (R)

12. I identify with my co-workers.

13. I feel a strong sense of belonging at my organization.

\section{Values}

14. Diversity is vital to an organization's success.

15 . I value diversity in my workplace.

16. It is good to work in a place where people are different from me.

17. Work teams are more efficient when people are similar. (R) 


\section{Schemas}

18. People at work base expectations of me on stereotypes. (R)

19. I do not feel stereotyped at work.

20. People lump me together with others at work. (R)

21. My co-workers judge me based on my character.

\section{Communication}

22. It is difficult to discuss tasks with my co-workers because of our differences.(R)

23. I have problems talking to co-workers who are different from me. (R)

24 . I communicate effectively across identity differences at work. 
Appendix B. Workplace Prejudice/Discrimination Inventory (WPDI; James, Lovato, Cropanzano, 1994)

1. I have sometimes been unfairly singled out because of my racial/ethnic group

2. Prejudice exists where I work.

3. Where I work all people are treated the same, regardless of their racial/ethnic group.

4. At work I feel socially isolated because of my racial/ethnic group.

5. At work minority employees receive fewer opportunities.

6. There is no discrimination on my present job.

7. Where I work members of some racial/ethnic groups are treated better than members of other groups.

8. At work people are intolerant of others from different racial/ethnic backgrounds.

9. Supervisors scrutinize the work of members of my group more than that of members of other racial/ethnic groups.

10. Where I work people of different racial and ethnic groups get along well with each other.

11. At my present job, some people get better treatment because of their racial/ethnic group.

12. There is discrimination where I work.

13. At work I am treated poorly because of my racial/ethnic group.

14. At my present place of employment, people of other racial/ethnic groups do not tell me some job-related information that they share with members of their own group.

15. Where I work promotions and rewards are not influenced by racial or ethnic group membership. 
Appendix C. Organizational Justice (Colquitt, 2001)

\begin{tabular}{|c|c|}
\hline Type of Organizational Justice and Items & $\begin{array}{l}\text { Source on which } \\
\text { item is based } *\end{array}$ \\
\hline \multicolumn{2}{|l|}{$\begin{array}{l}\text { Procedural Justice } \\
\text { Instructions: For the following items, think about your most } \\
\text { recent performance evaluation (formal or informal). } \\
\text { The following items refer to the procedures used to arrive at } \\
\text { the outcome of your performance evaluation. To what extent: }\end{array}$} \\
\hline $\begin{array}{l}\text { Have you been able to express your views and feelings during } \\
\text { those procedures? }\end{array}$ & $\begin{array}{l}\text { Thibaut \& Walker } \\
\text { (1975) }\end{array}$ \\
\hline $\begin{array}{l}\text { Have you had influence over the (outcome) arrived at by those } \\
\text { procedures? }\end{array}$ & $\begin{array}{l}\text { Thibaut \& Walker } \\
(1975)\end{array}$ \\
\hline Have those procedures been applied consistently? & Leventhal (1980) \\
\hline Have those procedures been free of bias? & Leventhal (1980) \\
\hline Have those procedures been based on accurate information? & Leventhal (1980) \\
\hline $\begin{array}{l}\text { Have you been able to appeal the (outcome) arrived at by those } \\
\text { procedures? }\end{array}$ & Leventhal (1980) \\
\hline Have those procedures upheld ethical and moral standards? & Leventhal (1980) \\
\hline \multicolumn{2}{|l|}{$\begin{array}{l}\text { Distributive Justice } \\
\text { Instructions: The following items refer to the outcome of your } \\
\text { performance review. To what extent: }\end{array}$} \\
\hline $\begin{array}{l}\text { Does your (outcome) reflect the effort you have put into your } \\
\text { work? }\end{array}$ & Leventhal (1976) \\
\hline $\begin{array}{l}\text { Is your (outcome) appropriate for the work you have } \\
\text { completed? }\end{array}$ & Leventhal (1976) \\
\hline $\begin{array}{l}\text { Does your (outcome) reflect what you have contributed to the } \\
\text { organization? }\end{array}$ & Leventhal (1976) \\
\hline Is your (outcome) justified, given your performance? & Leventhal (1976) \\
\hline \multicolumn{2}{|l|}{$\begin{array}{l}\text { Interpersonal Justice } \\
\text { Instructions: The following items refer to the person in charge } \\
\text { who conducted your performance evaluation. To what extent: }\end{array}$} \\
\hline Has he/she treated you in a polite manner? & $\begin{array}{l}\text { Bies \& Moag } \\
(1986)\end{array}$ \\
\hline Has he/she treated you with dignity? & $\begin{array}{l}\text { Bies \& Moag } \\
(1986)\end{array}$ \\
\hline Has he/she treated you with respect? & $\begin{array}{l}\text { Bies \& Moag } \\
(1986)\end{array}$ \\
\hline Has he/she refrained from improper remarks or comments? & $\begin{array}{l}\text { Bies \& Moag } \\
(1986)\end{array}$ \\
\hline
\end{tabular}


Taxonomy of Workplace Diversity 109

\begin{tabular}{|l|l|}
\hline $\begin{array}{l}\text { Informational Justice } \\
\text { Instructions: The following items refer to the person in charge } \\
\text { who conducted your performance evaluation. To what extent: }\end{array}$ & \\
\hline Has he/she been candid in his/her communications with you? & $\begin{array}{l}\text { Bies \& Moag } \\
(1986)\end{array}$ \\
\hline Has he/she explained the procedures thoroughly? & $\begin{array}{l}\text { Bies \& Moag } \\
(1986)\end{array}$ \\
\hline $\begin{array}{l}\text { Were his/her explanations regarding the procedures } \\
\text { reasonable? }\end{array}$ & $\begin{array}{l}\text { Shapiro et al. } \\
(1994)\end{array}$ \\
\hline $\begin{array}{l}\text { Has he/she communicated details in a timely manner? } \\
\text { Has he/she seemed to tailor (his/her) communications to } \\
\text { individuals' specific needs? }\end{array}$ & $\begin{array}{l}\text { Shapiro et al. } \\
(1994)\end{array}$ \\
\hline
\end{tabular}

Note: All items use a 5-point scale with anchors of $1=$ to a small extent and $5=$ to $a$ large extent.

* Citations reflect the source of the concepts measured by the scale items. 
Appendix D. Negative Affect (Watson, Clark \& Tellegan, 1988)

This scale consists of a number of words that describe different feelings and emotions. Read each item and then mark the appropriate answer in the space next to that word. Indicate to what extent [INSERT APPROPRIATE TIME INSTRUCTIONS HERE]. Use the following scale to record your answers.

$\begin{array}{lcccc}\mathbf{1} & \mathbf{2} & \mathbf{3} & \mathbf{4} & \mathbf{5} \\ \text { very slightly } & \text { a little } & \text { moderately } & \text { quite a bit } & \text { extremely } \\ \text { or not at all } & & & \end{array}$

distressed
upset
guilty
scared
hostile
irritable
ashamed
nervous
nittery
afraid

The authors of the scale have used PANAS with the following time instructions:

Moment (you feel this way right now, that is, at the present moment)

Today (you have felt this way today)

Past few days (you have felt this way during the past few days)

Week (you have felt this way during the past week)

Past few weeks (you have felt this way during the past few weeks)

Year (you have felt this way during the past year)

General (you generally feel this way, that is, how you feel on the average) 
Appendix E. Safety Climate (Zohar \& Luria, 2005)

Top management in this plant-company...

Reacts quickly to solve the problem when told about safety hazards.

Insists on thorough and regular safety audits and inspections.

Tries to continually improve safety levels in each department.

Provides all the equipment needed to do the job safely.

Is strict about working safely when work falls behind schedule.

Quickly corrects any safety hazard (even if it's costly).

Provides detailed safety reports to workers (e.g., injuries, near accidents.)

Considers a person's safety behavior when moving-promoting people.

Requires each manager to help improve safety in his- her department.

Invests a lot of time and money in safety training for workers.

Uses any available information to improve existing safety rules.

Listens carefully to workers' ideas about improving safety.

Considers safety when setting production speed and schedules.

Provides workers with a lot of information on safety issues.

Regularly holds safety-awareness events (e.g., presentations, ceremonies).

Gives safety personnel the power they need to do their job. 